\title{
القدرة التنبؤية للاتجاه نحو قبول الآخر والاستقرار الاسري كمؤشر لتعزيز الانتماء الوطني المدرك لدى عينة من الثباب السعودي الأني
}

\author{
فاطمة خليفة السيا \\ أستاذ علم النفس الإكلينيكي - قسم علم النفس ـ كلبة الآداب والعلوم الإنسانيةـ

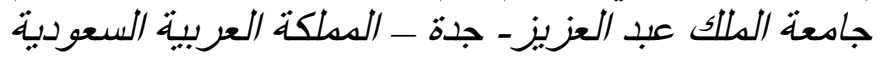

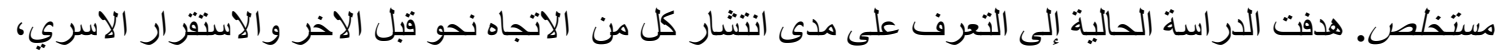

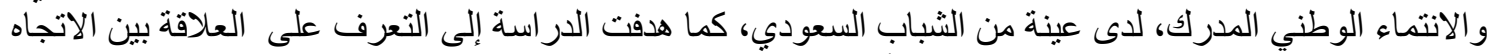

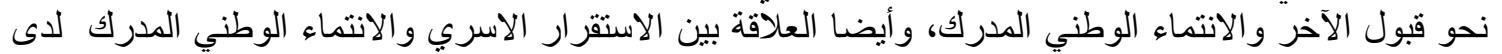

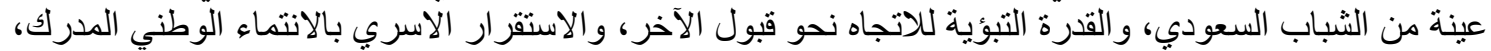

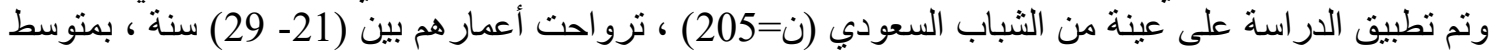

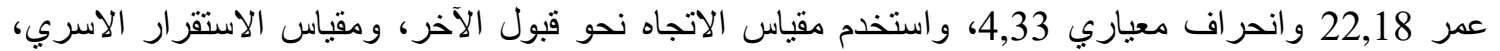

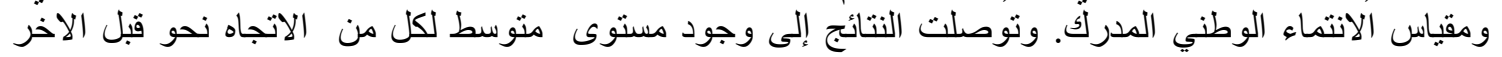

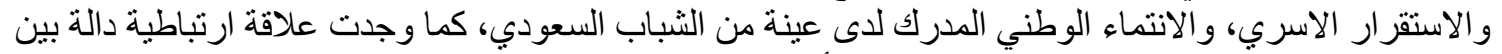

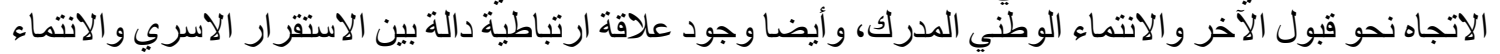

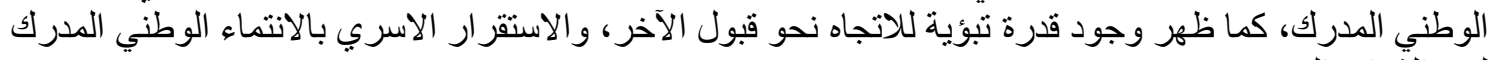

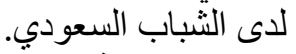
كلمات مفتاحية:ــ الاتجاه نحو قبول الآخر ـ الاستقرار الاسري ـ الانتماء الوطني المدرك ـ الثباب السعودي.

ويعد الانتماء للوطن احساس وشعور وادرالك نفسي

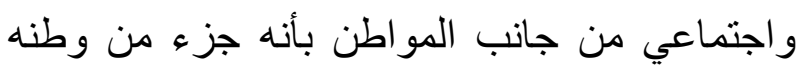
يحبه ويتعلق به، ويكن له الو لاء ويعتبر اتجاها ايجابيا مدعما بالحب يستشعره الفرد تجاه وطنه مؤكدا وجود

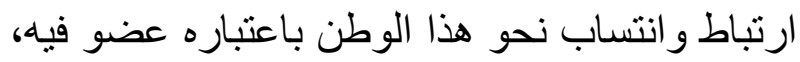
ويترجم بشكل من اشكال السلوك. (سامية شحاته،2012). وكلما زاد الشعور بالانتماء زاد

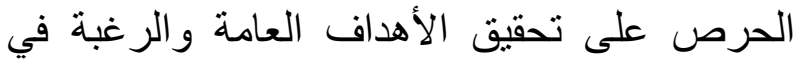
الإنجاز ، وبالتالي زيادة درجة التأثير الإجتماعي. Al (majajdah, 2010) كما يحتل قبول الآخر مكانة رفيعة في حياة البشر، نظرا لما يؤدية في حياتتا من دور كبير في تهيئة

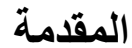

يعد الانتماء مطلبا ضروريا تصبو اليه كل نفس

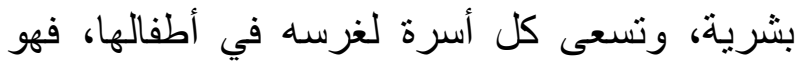
قضية اجتماعية تتأثر بالتغير ات السياسية و الاقتصادية

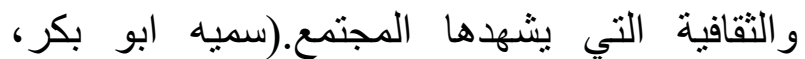
2013). كما يلعب الانتماء دور ا مهما في تحديد علاقة الافر اد بوطنهم الذي يعيشون فيه، فهو دافع وراثي

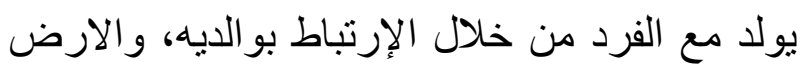
التي ولد فيها، و أيضا مكتسب ينمو من خلال مؤسسات المجتمع سواء بالمدرسة او الجامعة.(محمد اسماعيل

و غادة شحاته، 2014). 
قادرة على إعطاء خصائص واضحة ومميزة لهذه الأمة عن غير ها من الأمم.(مشهور سرور، 2015). وفي الآونة الأخيرة كثر الحديث عالميا عن موضوع الانتماء، بصورة تؤكد انتشار سلوكيات تنم عن الاحساس بعدم الانتماء بين قطاعات مختلفة من المجتمعات ، و إن بعض الثباب الآن أصبح يتصف لهف باللامبالاة والسلبية، وضعف الإنتاج و المشاركة وفقدان روح الإنتماء سواء للوطن الذي يعيش فيه أو العمل الذي يقوم به أو الكلية التي بدرس بها، و إذا كان بعض الناس في الغرب يشعرون بالاحباط لقلة ما يعرفونه عن موضوع الانتماء، فإن الواقع الاجتماعي في بلادنا العربية لا بعد بناءا مستقرا و إنما حركة مضطربة نحو أفق مفتوح يحتاج إلى غرس الإنتماء في أبنائه.(سامية شحاته، 2012). وتو اجه المجتمعات العربية في الوقت الر اهن تحديات فكرية ، ينبخي معها مساعدة الثباب على تتمية الوعي بالانتماء لوطنهم ، في ظل الظروف والمتغيرات الراهنة التي تؤدي الى ضعف الانتماء، ويمثل ذلك خطورة وتأثثر سلبي على المجتمع ، لذلك من المفيد اخضاع الانتماء الوطني للار اسة في ظل عالم متغير ثقافيا مليء بمعدلات العنف والانحر اف الذي يستهدف

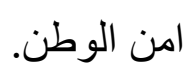
وتعد حقيقة قبول الآخر تربية مستمرة، لذلك كان لابد للمؤسسات التعليمية أن تحافظ على تللك التربية وتتميتها بين أعضائها، ومن ثم تنشئة الأبناء منذ الصغر على قيم الحوار وقبول الرأى الآخر مهما اختلف وتباين معه. (فاروق مرزوق،2016). كا اصبح نشر ثقافة قبول الاخر حاجة ملحة يجب غرسها
النفوس وصفائها وتقبلها لهفوات وأخطاء الآخرين، فعندما يصمم كل طرف على أن يغلب رأيه على رأي الآخر فإنها يقع في مناقضة صريحة لمعايير الحوار العقلاني الموضو عي،و الوقوع في استخفاف كل منهما للآخر في منزلته وثقافته وجنسه ولونه. (فاروق مرزوق،2016). حيث بعد قبول الآخر المفهوم الأشمل لمحبة الآخر و التعايش السلمي معه. (ميشيل مجلع،2016). بالاضافة إلى ذلك يعد الاستقرار الأسري أحد أبرز

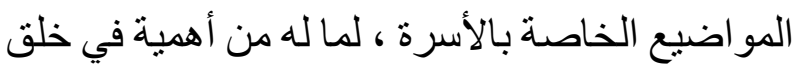
مناخا اجتماعيا مميز ا داخل نطاق الأسرة، ومساعدة الأبناء على إثباع احتياجاتهم النفسية والاجتماعية، ويسود جو المودة والرحمة في الأسرة. (Aldoughlia, 2019) العلاقات الأسرية على طبيعة المناخ الأسري و الذي يمثل الجو السائد في الأسرة ككل، فنجاح العلاقات بين

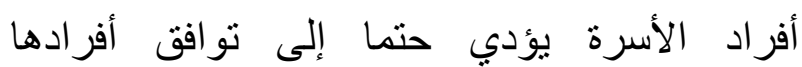

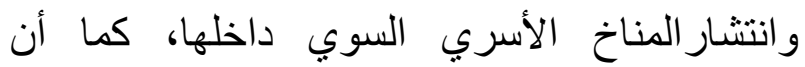
اضطر اب هذه العلاقات يؤدي أيضا إلى انحراف التفاعلات الأسرية عن نموها الطبيعي وما ينشأ عن ذلك من تفككها ومعاناة الأسرة من التونر والصراع والانشقاق وكل ذلك يؤثر سلبا على النمو النفسي و السلوكي و الاجتماعي للأبناء.(داليا حافظ، 2015).

\section{مشكلة الدر اسة لمبة}

الانتماء موضوع مهم عند الأمم التي تحرص على ملى الته ترسيخه فى ناشئتها وفق محددات معينة تسهم في تشكيل هذا الانتماء، وتتميته وتطويره بحيث تصبح 
ـ هل توجد قيمة تنبؤية دالة لكل من الاتجاه نحو قبول الاخر والاستقرار الاسري بالانتماء الوطني المدرك

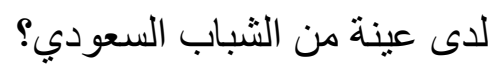

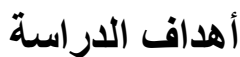

تهدف الدراسة الحالية الى الكشف عن:

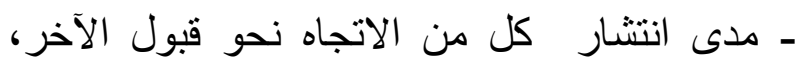

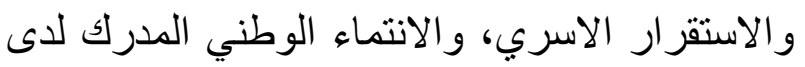
عينة من الثباب السعودي. ـ العلاقة بين الاتجاه نحو قبول الابعد الاخر والانتماء

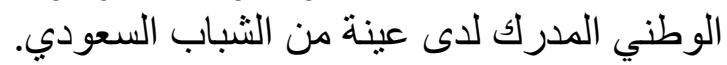

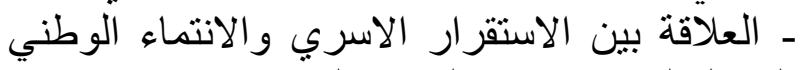

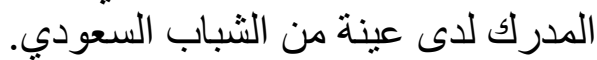

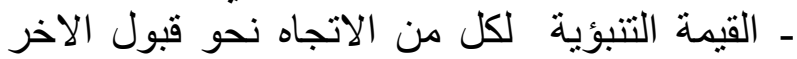

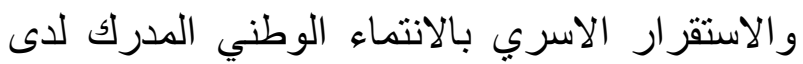

\section{عينة من الثباب السعودي. الهمية الدراسة \\ أولا:- الاهمية النظرية}

ـ تساهم الدراسة في القاء الضوء الأه على متغير الإنتماء

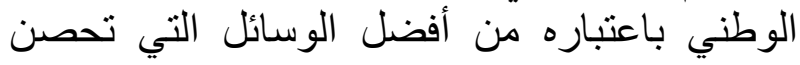
الثباب ضد الاحباطات المتنو عة كالبطالة والفي الفراغ

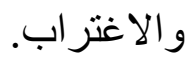
ـ تستمد الدر اسة أهميتها من عينة الدر اسة وهم الثباب

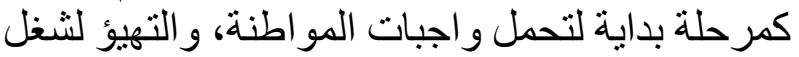

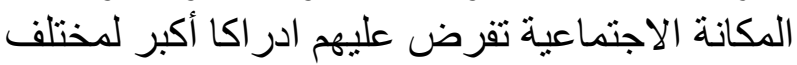

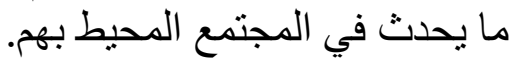
- توفير معلومات عن متغير مهم لدى الدئ الثباب الجامعي

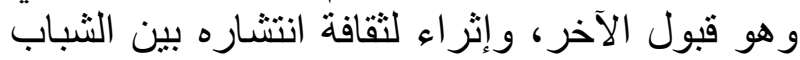

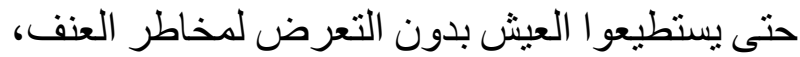

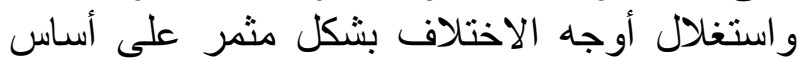

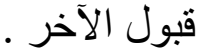
ـ قد تفيد نتائج الدر اسة المسئولين بوز ارة التعليم العالي

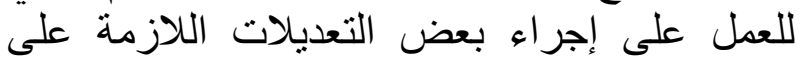

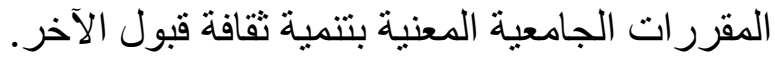

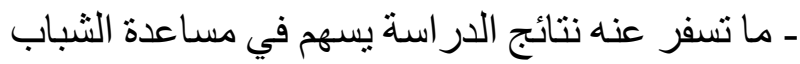
على تحقيق الانتماء الوطني، وبالتالي زيادة تحقيق
في نفوس وعقول هذا الجيل منذ الصغر لكي يسهر بشكل فعال في خلق جيل واع قادر على تحمل هلى لهيل المسئولية وقيادة المرحلة القادمة بشكل ايجابي، ويعتمد ذلك على الاستقرار الأسري ووجود علاقات أسرية ناجحة تقوم على التفاعل الدائم بين أفر اد الأسرة جميعا، و التي تهيئ للأبناء الحياة الاجتماعية و الدينية

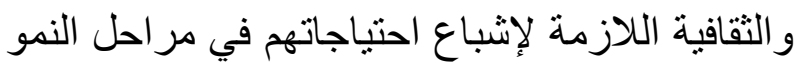
المختلفة ، مما يحقق أكبر قدر من التماسك و التعاون

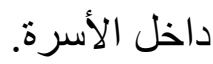
وجاءت الدراسة الحالية كمحاولة للوقوف على الدى

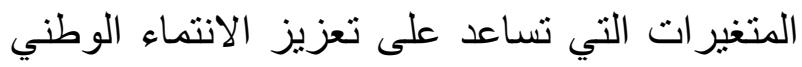

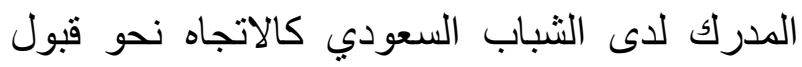
الاخر ، والاستقرار الاسري.وانطلاقا من هذا التناول

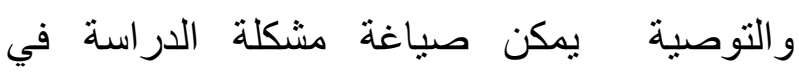

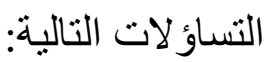

\section{أسئلة الاراسة}

ـ ما مدى انتشار الاتجاه نحو قبول الآخر لدى عينة

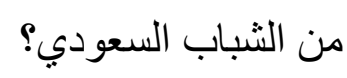
ـ ما مدى انتشار الاستقرار الأسري لاى عينة من

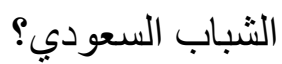
ـ ما مدى انتشار الانتماء الوطني المدرك لدى عينة

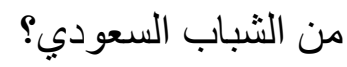
- هل توجد علاقة ارتباطية بين الاتجاه نحو قبول الاخر و الانتماء الوطني المدرك لدى عينة من الثباب السعودي؟ ـ هل توجد علاقة ارتباطية بين الاستقرار الاسري

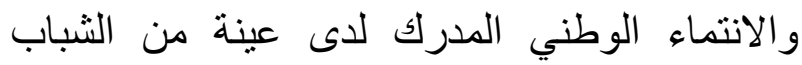

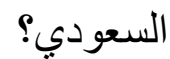


يعرف الإستقرار الأسري بأنه "حالة من التماسك بين أفراد الأسرة والقدرة على تحقيق مطالبهم وسلادة الإنه

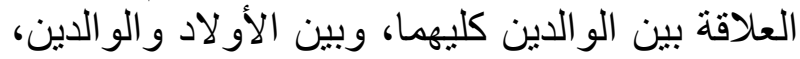

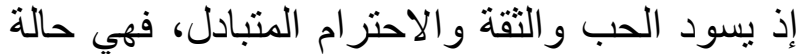

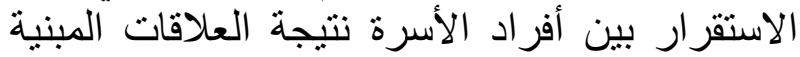

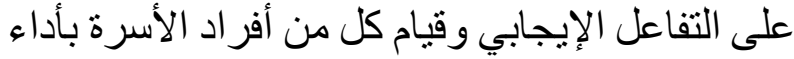

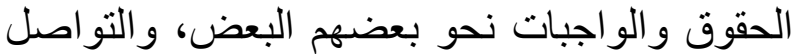

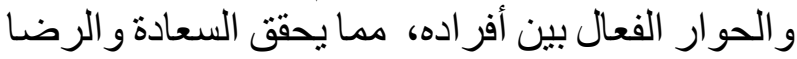

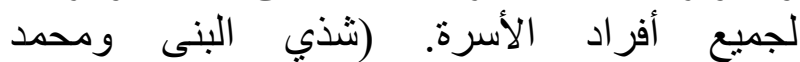
الحور اني،2019) ومن الصفات التي تثميز بها الأسرة المستقرة:

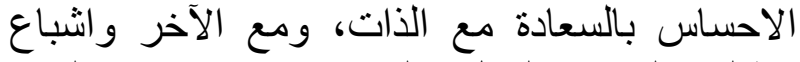

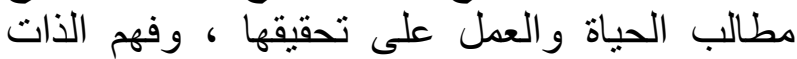

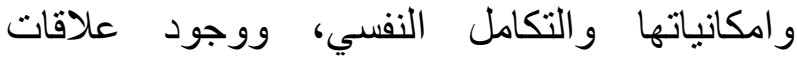

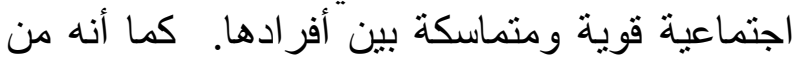

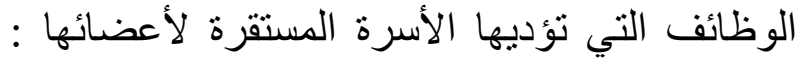
تكوين الشخصية و اكساب المكانة و التنشئة الاجتماعية لاعنية

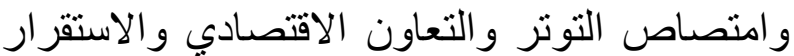
النفسي.(صفاء مرسي، 2012). وتعرفٌه الباحثة إجر ائيا بأنه تماسك أفر اد الأسرة نتيجة

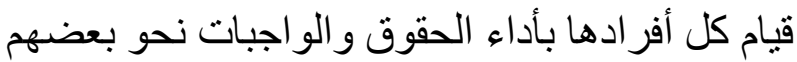

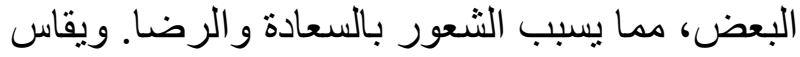

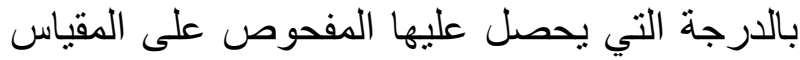
المستخدم في الدر اسة الحالية. ومن مقومات الإستقر ار الأسري الاختهنيار الموفق،

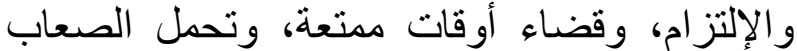

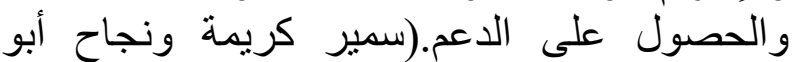

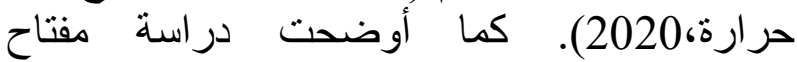
بالحاج(2017)انه لكي يتسنى للأسرة القيام بوظائفعا

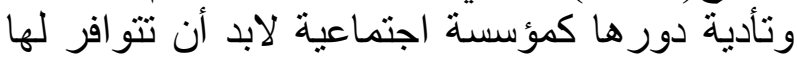

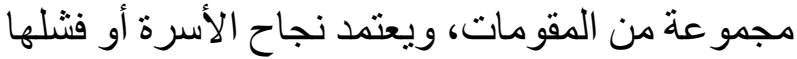

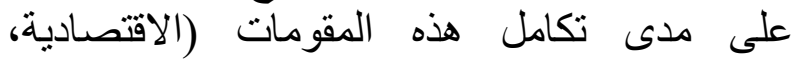
و الصحية ، و الاجتماعية) وتر ابطها.

الانتماء الوطني

إن مفهوم الانتماء الوطني من المفاهيم التي يولا بها الفرد من خلال ارتباطه بو الديه وبالأرض الأرض التي ولد

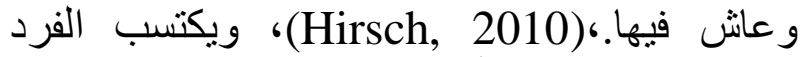
الانتماء الوطني من أسرته التي تربت و عاثت على على
الأهداف و الر غبة في الانجاز ، بالإضافة الى مساعدة

التربويين في عملية التخطبط لبناء العقول المفكرة.

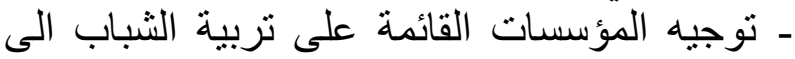

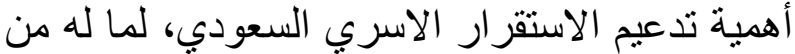

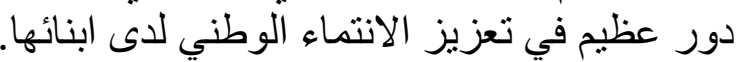
ثانيا:- الاهمية التطبيقية تعزية - ما ستسفر عنه نتائج الدراسة يساعد فئه في تصمئم برامج ارشادية للشباب تعمد على تعزيز الإن الانتماء الوطني، لتخريج شباب قادرين على الابداع و التنمية تعنية الوطنية الثاملة.

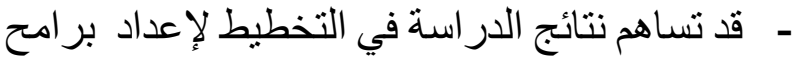

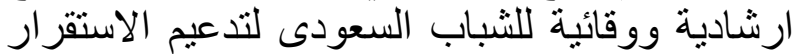
الأسري وقبول والئ الآخر.

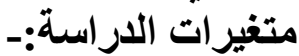
الإتجاه نحو قبول الآخر أوضحت ميثل مجلع(2014) بأن قبول الآخر هول هو الآنر

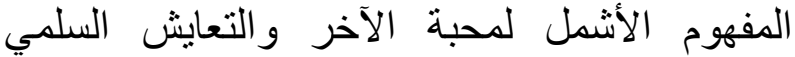

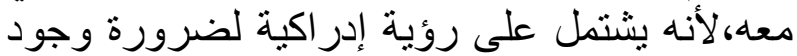

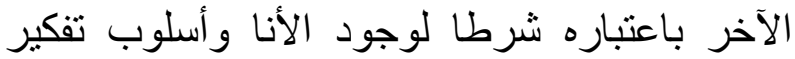

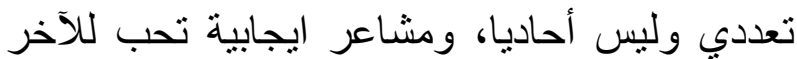

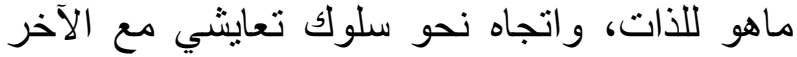
وليس سلوكا اقصائيا. كماعرفته صفاه واء الدسوقي وثريا

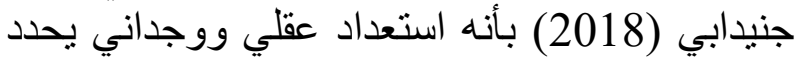
درجة الرضا بوجود الآخر واحتماله والتعامل معه و الاتفاق ضمنا على احتر امه الهـ

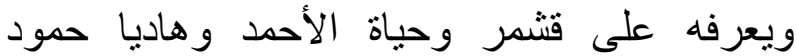
وسميرة عريس(2019) بأنه استجابة طالب الجامعة وهئ التي يدرس فيها الطالب التي تعكس تقبله لأفكار

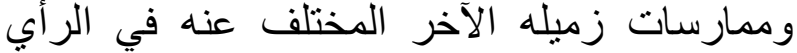
و الفكر و المصالح و العادات و التقاليد و التعليم و المهنة

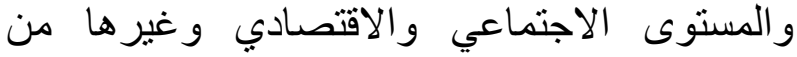
جوانب الاختلاف والإقرار بحقه في ممارسة حقوقه كافة في المجتمع وصو لا للعيش معه في سلام.

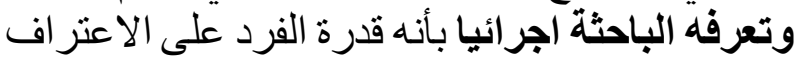

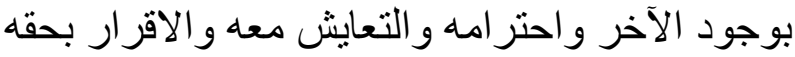
في التعبير عن ارائه وتقبلها. الاستثرار الأسري 
وتعرفه الباحثة اجرائيا بأنه ارتباط الفرد بوطنه

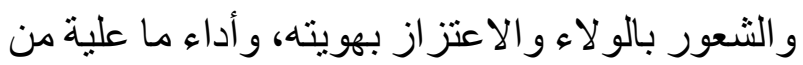
واجبات تجاه هذا الوطن كالحفاظ على ممتلكاته و الدفاع عن مصالحه و المساهمة في حل مشكلاته مما لهاه

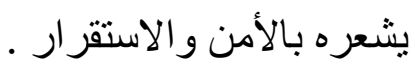

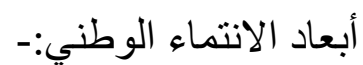
1- الهوية الوطنية: يسعى الانتماء إلى توطيد الهوية التي هي دليل على وجوده، ومن ثم تبرز سلوكيات الأفراد كمؤشرات للتعبير عن الهوية، وبالتالي الانتماء الوطني. 2- الجماعية الوطنية:- إن الروابط الانتمائية تؤكد

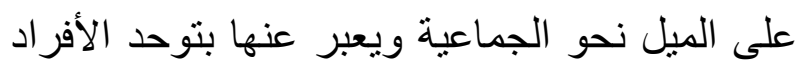
مع الهدف العام للجماعة التي ينتمون اليها داخل الوطن الواحد في سلوك من التعاون والتكافل و التماسك و الرغبة الوجدانية في المحبة و التفاعل الت لون 3- الولاء الوطني: إنه يدعم الهوية الذاتية ويقوي

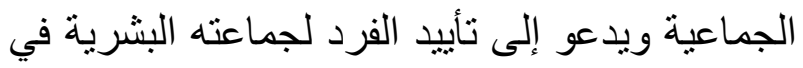
وطنه، ومع أنه الأساس القوي الذي يدعم الأساس لداسيد القوي الذي يدعم الهوية إلا أنه في الوقت ذاتها لهانه يعتبر

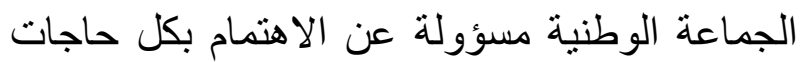
أعضائها بهدف الحماية الكلية.(على عو اد،2015).

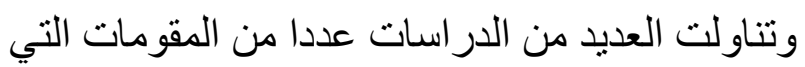

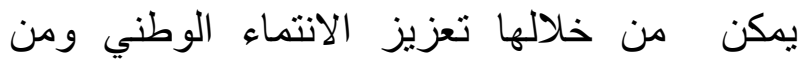

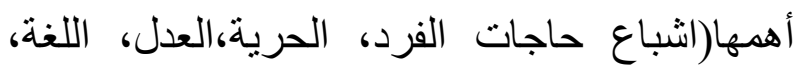
در اسة تاريخ الوطن وأمجاده.( محمد السعايدة وحامد طلافحة،2018).

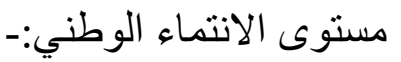

الولاء و الوفاء للاين و الوطن والقيادة، وينمو هذا

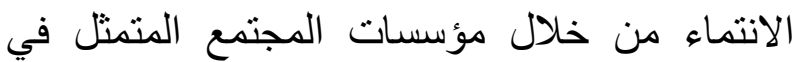

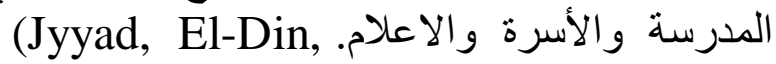
2012)

ويعرف بأنه اتجاه مدعم بالحب، يستشعره الفرد تجاه وطنه مؤكدا وجود ارتباط و انتساب نحو هذا الوطن باعتباره عضو فيه ويشعر نحوه بالفخر و الو لاء ويعتز بهويته وتوحده معه ويكون منشغلا ومهمو ما بقضاياه، محافظا على مصالحه وثرو اته ومر اعيا الصالح العام

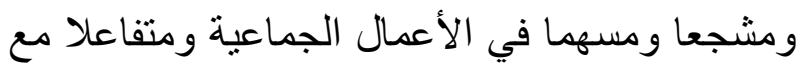

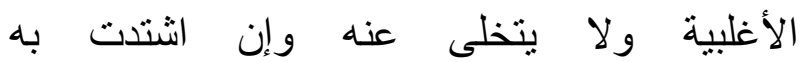
الأزمات.(عنمان العامر،2010). وتعرفه خلود ملياني(2017) بأنه الشعور الداخلي الثاني و الر ابط القوي الذي يربط بين الفرد ووطنه، ويتجسد

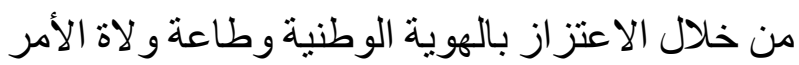
و الالتفاف حولهم والالتزام بالنظم و القو انين السائدة ، و العمل على المحافظة على الوطن وحماية ممتلكاته

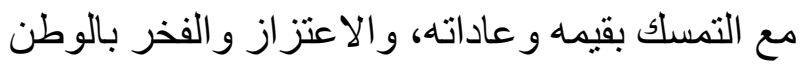
، و التضحية بالنفس و النفيس دفاعا عن الوطن.

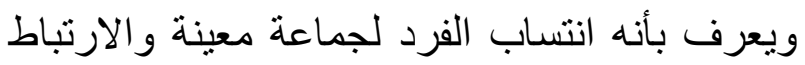

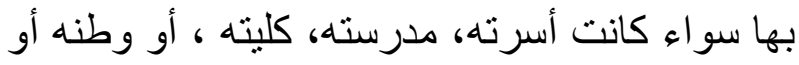
حزبه السياسي وله ما لأفر ادها من حقوق و عليه وما

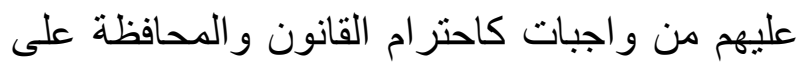
الممتلكات العامة والمشاركة في حل مشكلات

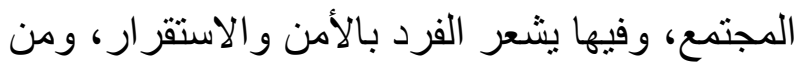
ثم يأتي و لاءه للجماعة فيكون على استعداد للتضحية في سبيلها.( وليد محمد وعاصم اسماعيل و أماني

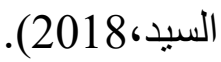


كما تناولت دراسة فاروق مرزوق(2016) التعرف

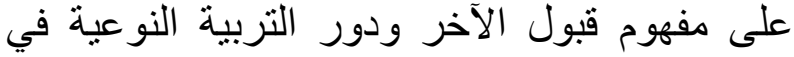
تنميته، وواقع قبول الآخر لآى الآى الطالب المعلم

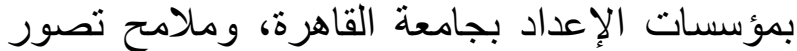

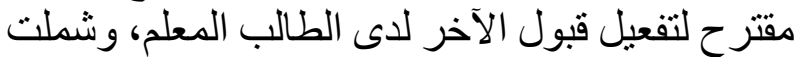
الاراسة (500) من الطلبة المعلمين بكليتي رياض الطئ

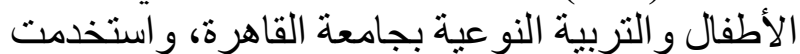

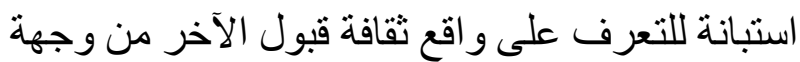
نظر الطلبة المعلمين، وتوصلت النتائج إلى وجود درجة متوسطة من محاور قبول الآخر لدى الطلبة الطية

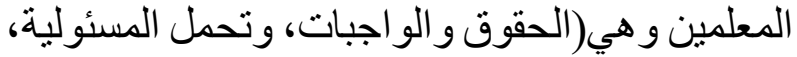

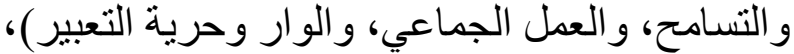

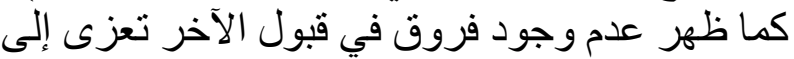
الجنس، والمشاركة في الأنشطة الجامعية، و والكلية،

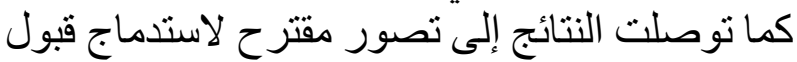
الآخر في بر امج إعداد الطالب المعلم. وهدفت در اسة مروى اسماعيل(2017) قياس فعالية برنامج قائم على بعض القرى القضايا السياسية لتنمية

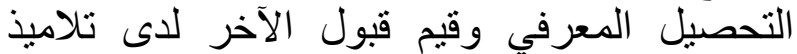

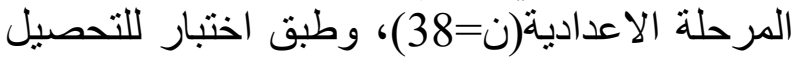

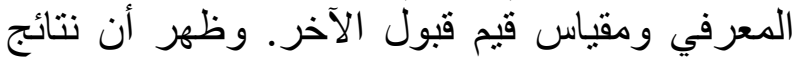

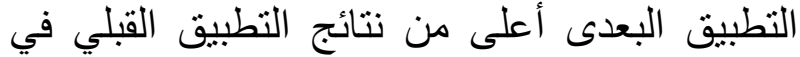
اختبار التحصيل المعرفي وقيم قبول الآليج الترل وكثفت دراسة الجوهرة السهلي فئل و و وألفت العربي(2018) عن دور القصص في تنمية قبول

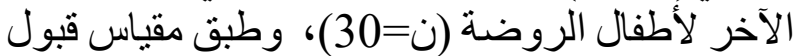

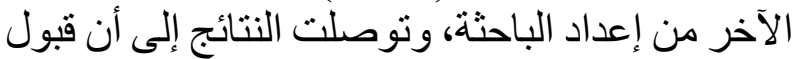

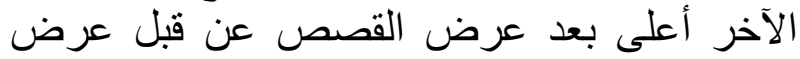

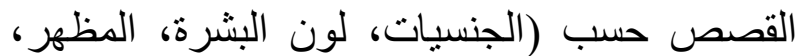

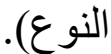
و اهتمت در اسة على قثنمر وحياة الأحمد و هاديا حمود وسميرة عريس(2019) بالتحقق من و اقع ثقافة قبول الآخر في الجامعات الفلسطينية واللبنانية والأردنية

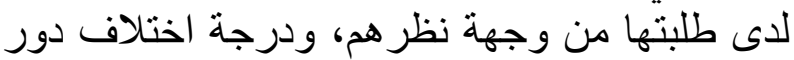
هذه الجامعات في تعزيز ثقافة قبول الآخر باختلاف

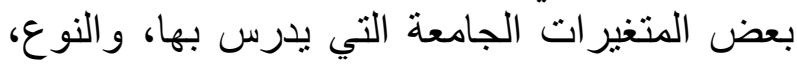
وتكونت عينة الدر اسة من (852) من طلبة الجنات الجامعات منهم (312) من فلسطين، (287) من لبنان، (253) من (252)
- المادي ويقصد به كون الفرد جزءا من جماعة

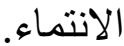
ـ الظاهري(اللفظي) ويكون بالتعبير عن مشاعر الفرد تجاه الجماعة التي ينتمي اليها.

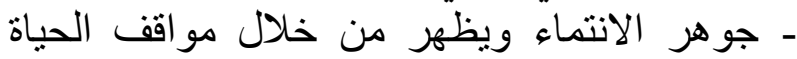
الفعلية. ـ ـ من حيث الاستمر ارية فالانتماء الدئم يكون للأسرة

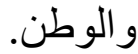
ـ ـ طويل الأجل مع الجيران و أصدقاء العمل. ـ قصير الأجل مع زملاء الدراسة. - من حيث الايجابية و الذوبان في شخصية الجماعة. ـ ـ انتماء سوي يدعم قيم المجتمع. - مرضي ضد قيم المجتمع . .( وليد محمد و عاصم

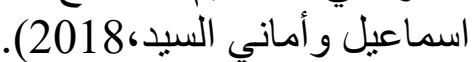

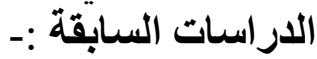

المحور الأول:- دراسات تناولت الإتجاه نحو قبول الآخر

يوجد ندرة في الدراسات العربية التي اهتمت بهذا

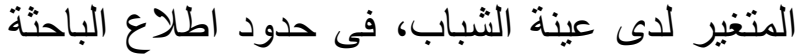

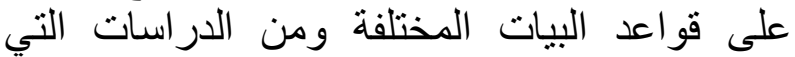
اهتمت بقيول الآخر دراسة ميشيل مجلع (2014)

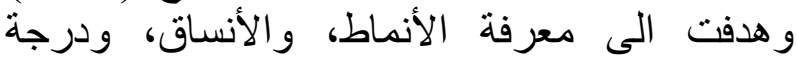

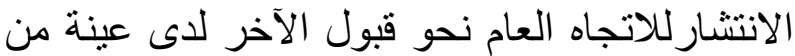

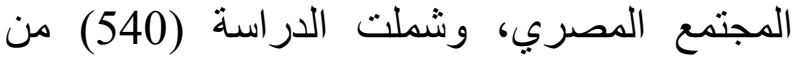
الذكور والاناث في المرحلة العمرية من (65-14)

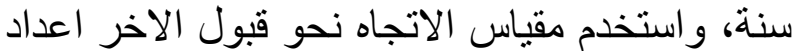

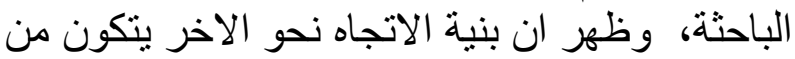
عدة عناصر فكرية، وادر اكية، ووجدانية، الانية، وسلوكية، وينتظم في ثلاثة مجالات (رؤية الاخر ، ورؤية الذات، ورئة ورؤية تحريرية)تتسق من عامل و احد هو الاتجاه نحو الأنو قبول الاخر، وبلغت نسبة الانتشار (75\%).

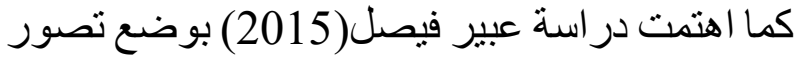

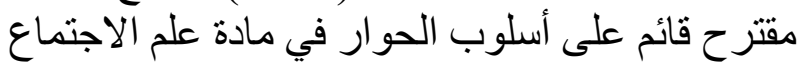

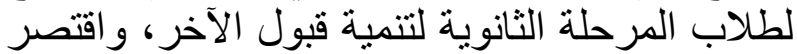

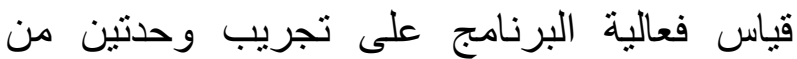

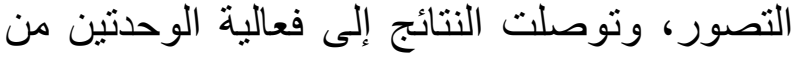

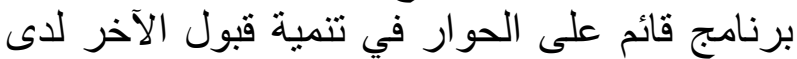
طلاب المرحلة الثنانوية. 
النتائج وجود مستوى مرتفع من التواصل الأسري

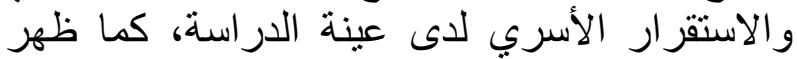
وجود علاقة طردية بين التو الصل الأسري و الإستقر ار الأسري.

المحور الثالث:- دراسات تناولت الإنتماء الوطني

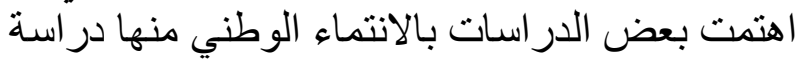

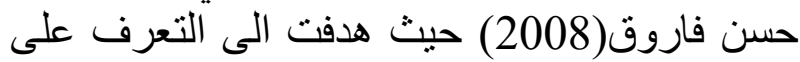

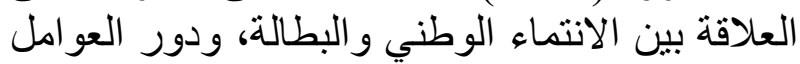

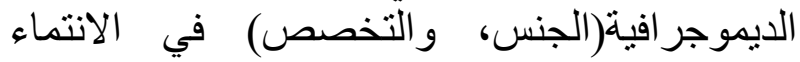
الوطني، وشملت الدراسة (400) من خريجي جامعة

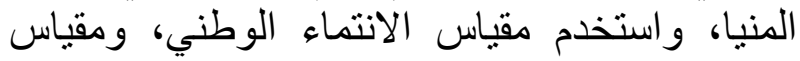

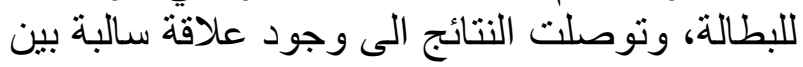

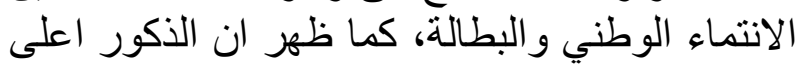
من الاناث في الانتماء الوطني.

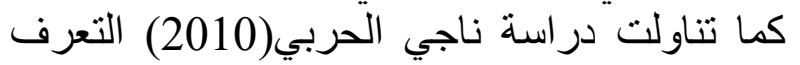
على دور منهج التربية الوطنية في تعزيز الانتية نئماء

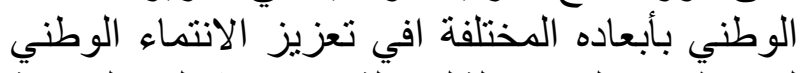

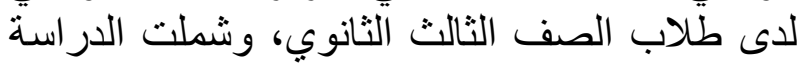

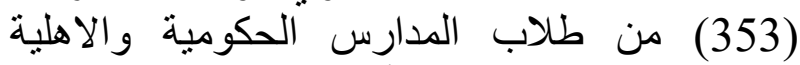
بالمدينة المنورة، وظهر أن مدى انتشار الانتماء

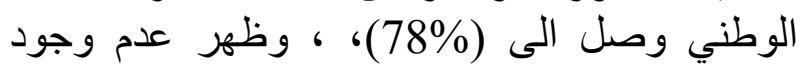

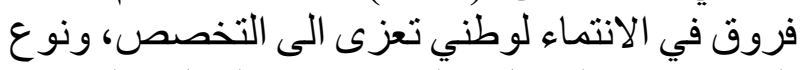

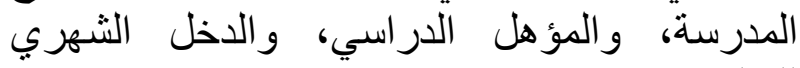

وسعت الدين. دراسة محمد اسماعيل وغادة وشحاته (2013)إلى التعرف على ملى مستوى الانتماء الوطني

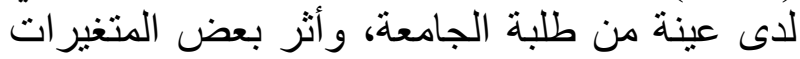

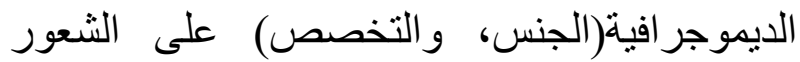
بالانتماء الوطني، وشملت الدر اسة (446) من طلاب التبات

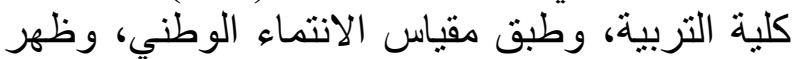

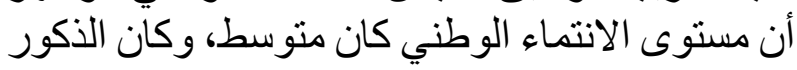

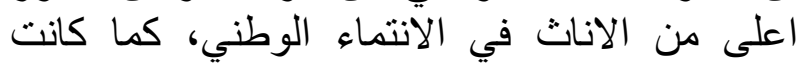
الاقسام العلمية اعلى من الاقنسام الادبية في الانتية الأماء الوطني.

وتناولت دراسة حسام ابو بكر(2013) العلاقة بين

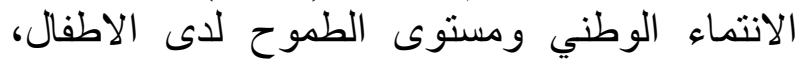
و الفروق بين الذكور والاناث في الانتماء الوطني

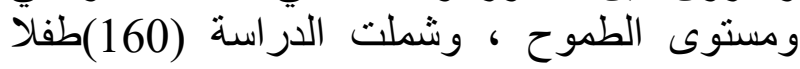

من الأردن، و واستخدم مقياس قبول الآخر، واتضح

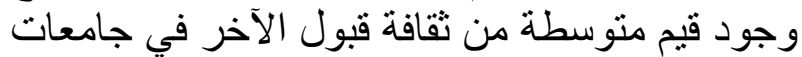

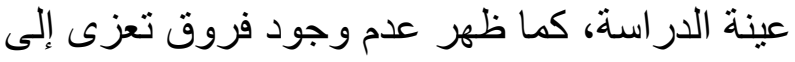

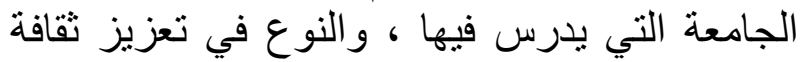
قبول الآخر. المحور الثاني:- دراسات تناولت الإستقرار الأسري

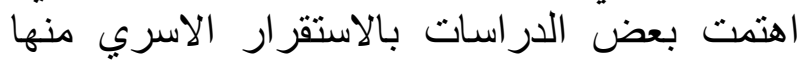

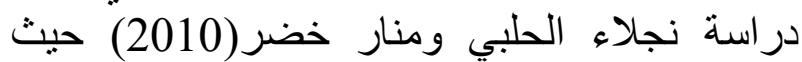
بحثت العلاقة بين إدارة الوقت لداء لدى الثباب و وعلاقته

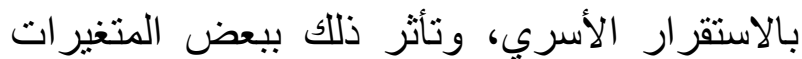

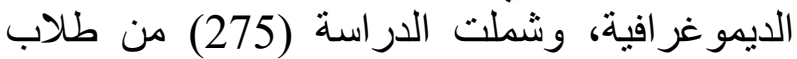

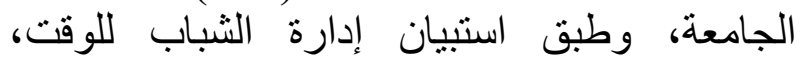
واستبيان الاستقرار الأسري، وتوصلت إنت النتائج إلى

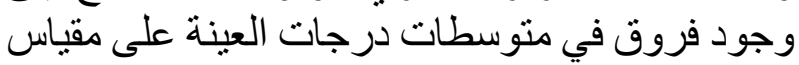

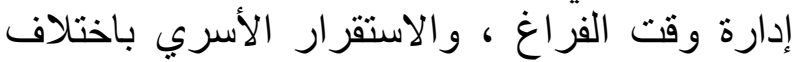

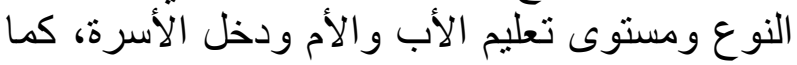

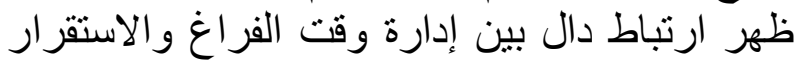
الاسرى. كما هدفت دراسة زينب عبد الجليل ونورة الزهراني(2011) الى التعرف على على العلاقة بلى بين الاستقرار الاسري ودرجة مشاركة الزوجة لزوجة الزيها

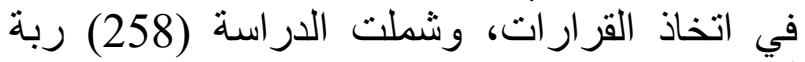
أسرة ،وظهر وجود ارتباط بين الاستقرار الاسري،

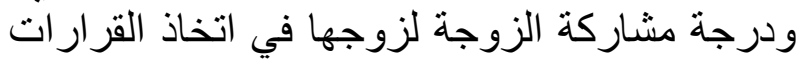
الاسرية. وتتاولت دراسة صفاء مرسي (2012) العلاقة بين الذكاء الوجداني والاستقرار الاسري لدرية لدى عينة من

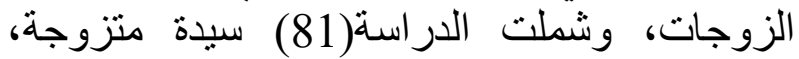
واستخدم مقياس الذكاء الوجداني، ومقياس الاستقرار

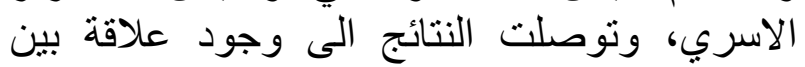
المتغيرين لدى عينة الدر اسة.

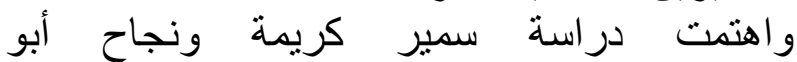

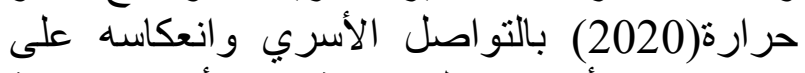

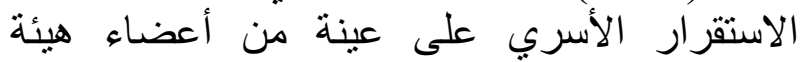
التدريس المتزوجين بكلية التربية بالزواية، واشنية واشتملت ألتين

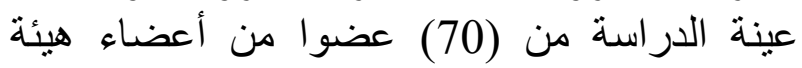

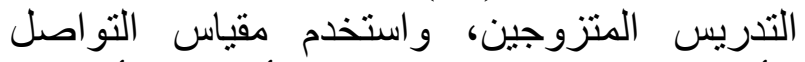
الأسري ، ومقياس الاستقرار الأسري. وأظهرت التوان 
- يوجد انتشار للاتجاه نحو قبول الآخر لدى عينة من

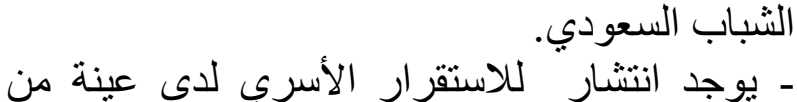

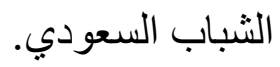
- يوجد انتشار الانتماء الوطني المدرك لدى عينة من

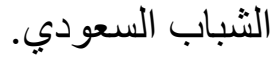
- توجد علاقة ارتباطية دالة احصائيا بين الاتجاه نحو الأبح

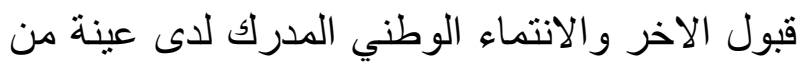

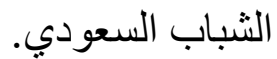

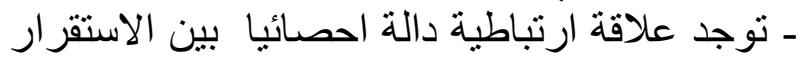

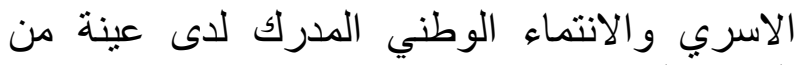
النشباب السعودي.

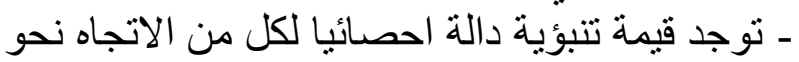

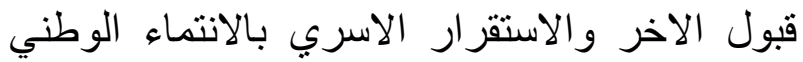

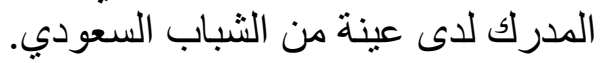

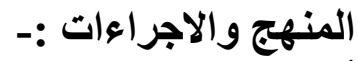
أولا:- المنهج المستخدام

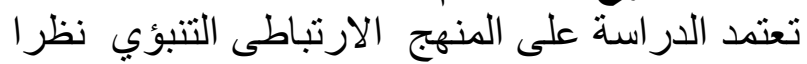

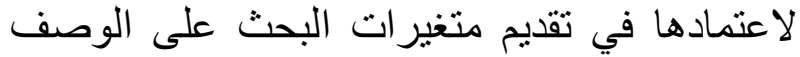

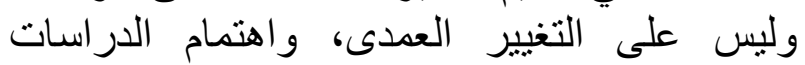
بالكثف عن المتغيرات النفسية بتشكيل الانتماء التئاء

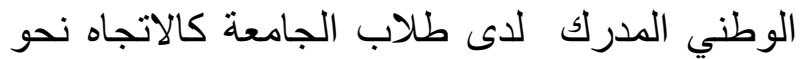
قبول الاخر والاستقرار الاسري وهذا لإنا أمر له أولويته

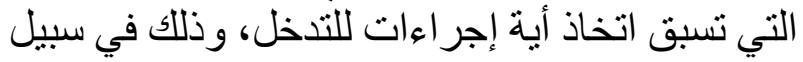

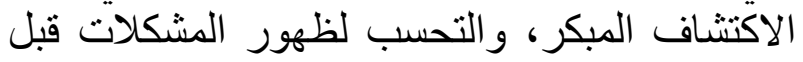
تفاقمها فيما يعرف بالوقائة الونية من الارجة الأولى.

$$
\text { ثانيا:- العينة }
$$

تكونت عينة الدا رسة في صورتها النهائية من (205) من طلاب جامعة الملك عبد العزيز بكليتي الاعني الآداب

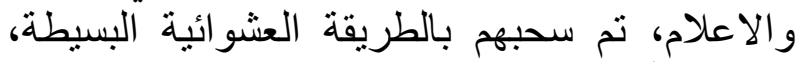

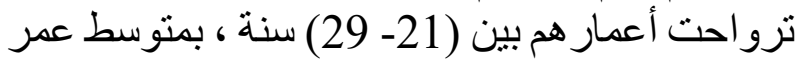

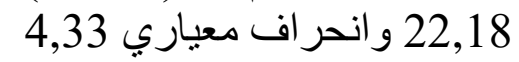

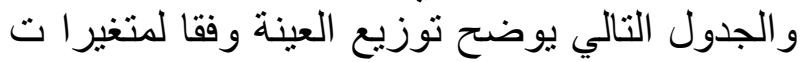
الجنس ، و العدر ، و الحالة الاجتماعية، ، و والمسنوى لئن

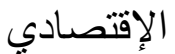

وطفلة بالمدارس الحكومية، واستخدم مقياس الانتماء

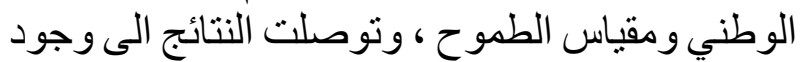

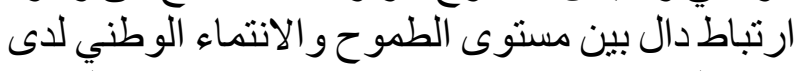

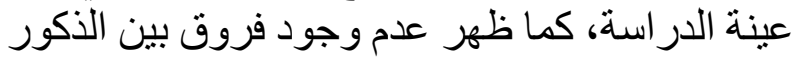

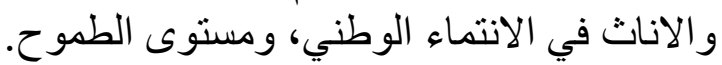
و هدفت دراسة نجوى السرحاني(2014) اللى الى بناء

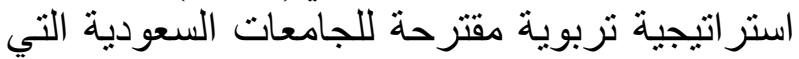

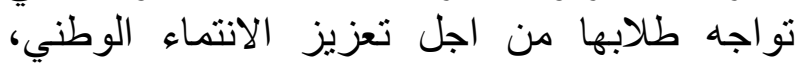
وشملت الدراسة عينة من اعضاء هيئة التدريس التهاء

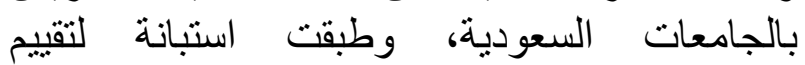

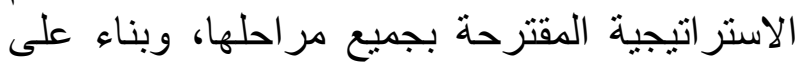
نتائج الدراسة اوصت الباحثة بتنبني الاستر اتيجية التئية التربوية المقترحة لدور الجامعات السعودية لتعزيز الإنية لإنية الانتماء الوطني لطلابها. تعليق عام على الاراسات السابقة:-

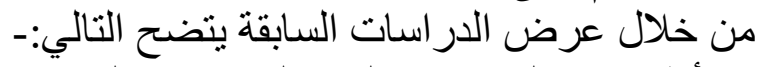

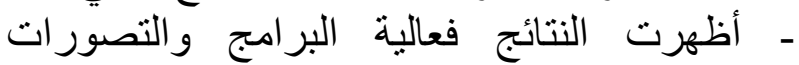
المقترحة من خلال الدراسات في تنمية قبول الإل الآخر لاى فئات مختلفة (المعلم، الطلاب و والأطفال).

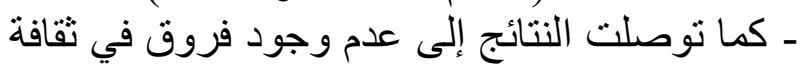
قبول الآخر تعزى إلى (الجنس، الكلية، والتخصص في في

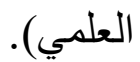
ـ توصلت بعض الدر اسات السابقة بوجود ارتباط بين

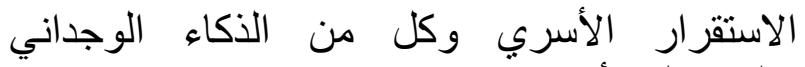

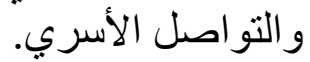

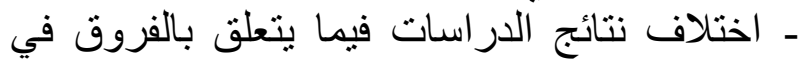

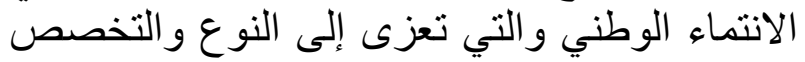

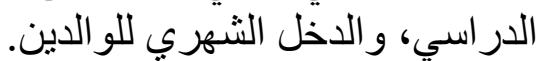

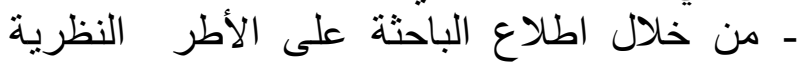

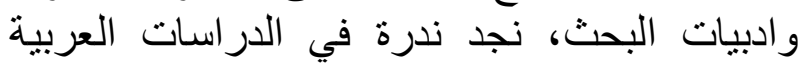
والأجنبية التي اهتمت بتناول العلاقة بين متغيرات

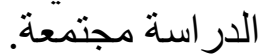
ومن خلال العرض السابق يمكن صياغة فروض

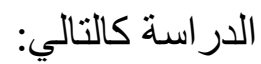

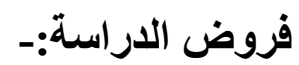

جدول (1) خصاص عينة الدراسة وفقا لبعض المتغيرات الديموجرافية

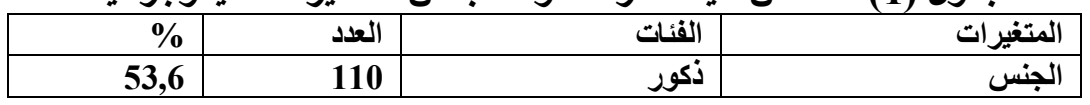




\begin{tabular}{|c|c|c|c|}
\hline 46,4 & 95 & إناث & \\
\hline 65,8 & 135 & من 24-21 & \multirow[t]{2}{*}{ العمر - العر } \\
\hline 34,1 & 70 & من 25-29 & \\
\hline 68,3 & 140 & أعزب & \multirow[t]{2}{*}{ الحالة الإجتماعية } \\
\hline 31,7 & 65 & متزوج & \\
\hline 14,6 & 30 & منخفض & \multirow[t]{3}{*}{ المتستوى الإقتصادي } \\
\hline 58,5 & 120 & متوسط & \\
\hline 26,8 & 55 & مرتفع & \\
\hline
\end{tabular}

عبار ات المقياس بالاختيار من (نعم،إلى حد ما، لا)،

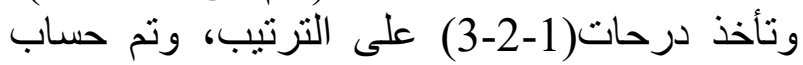

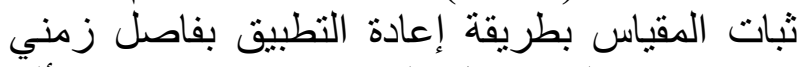
اسبو عين، وبلغ معامل التبات(

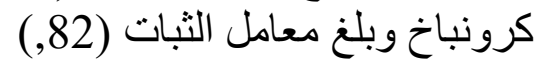

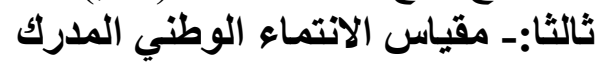

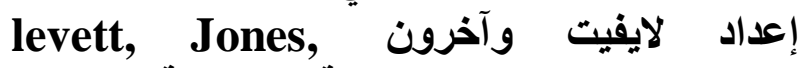
Bourgeois,2007 صابر(2012) يتكون المقياس من (34) عبارة تعكس ثناثنة مكونات

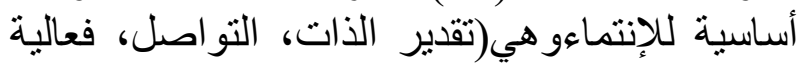

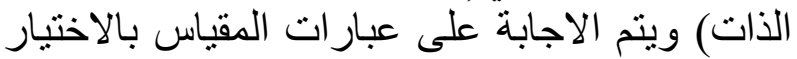
من (غير حقيقي تماما، نادرا، أحيانا، حقيقي غالبا، أبا،

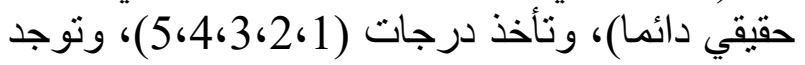

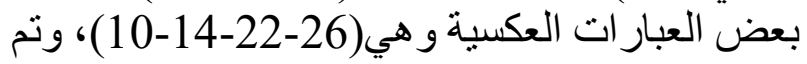
التحقق من الخصائص السيكومترية للمقياس التهاس على

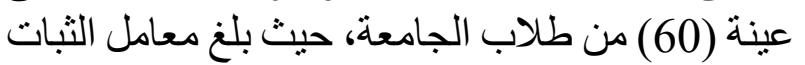

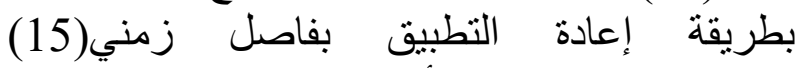

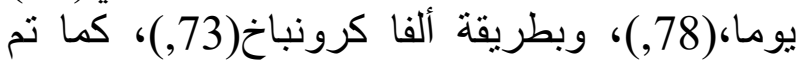

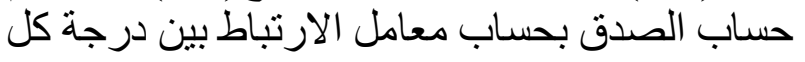

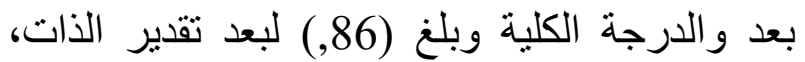

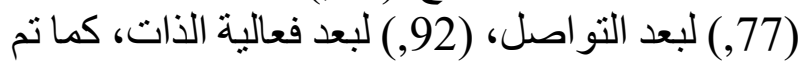

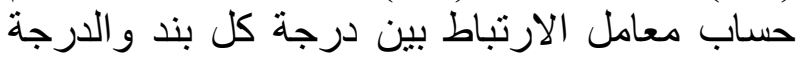

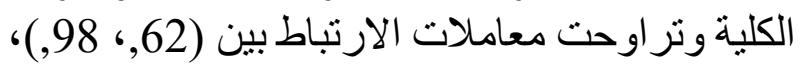

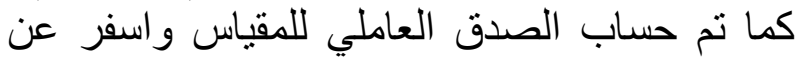

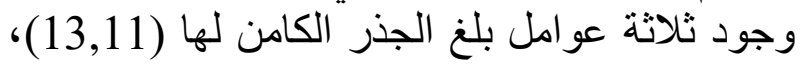
واستقطب (44,1) و من التباين الكلي.

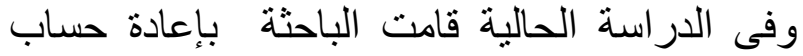

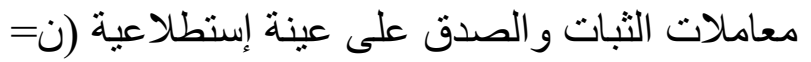

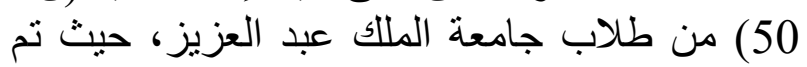
حساب الارتباط بين درجة كل بند و الدرجة الكلية

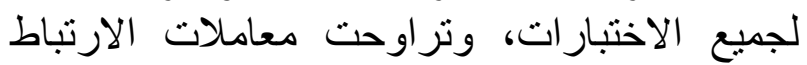

بتضح من الجدول السابق تباين في توزيع أفر اد العينة

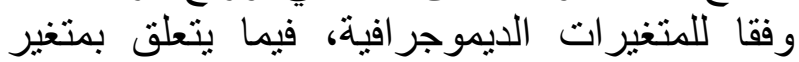

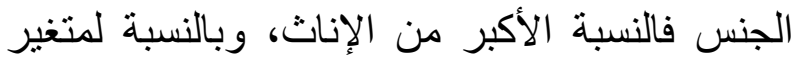
العمر فالنسبة الأكبر تقع في الفئة من (24-21) سنة، الأنة

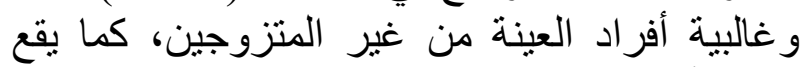
غالبية أفر اد العينة في المستوى الإقتصادي المتوسط.

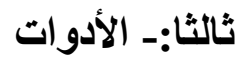
أولا: مقياس الاتجاه نحو قبول الآخر إعداد ميشل

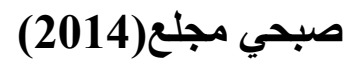
يتكون المقياس من (50) عبارة بعضئها موجب

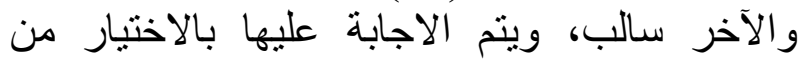

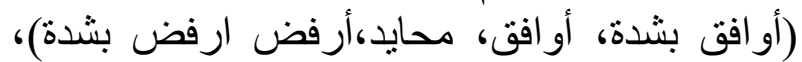

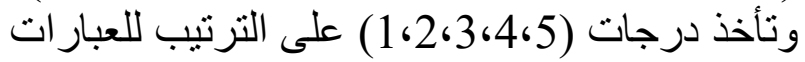

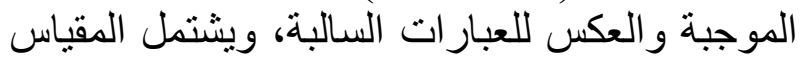
على ثلاثة أبعاد(رؤية الآخر ، رؤية الذية الذات، رؤية رئية

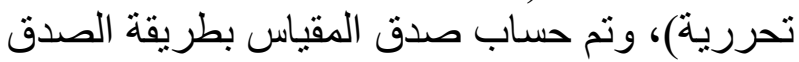

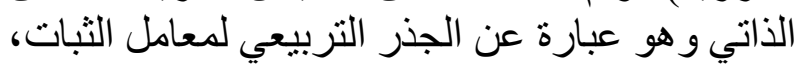

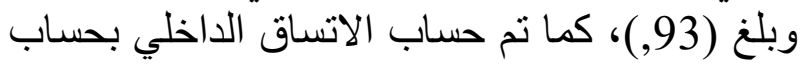

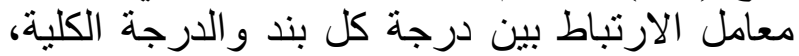

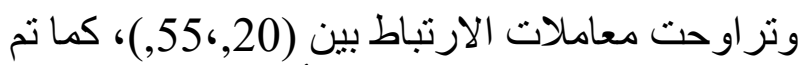

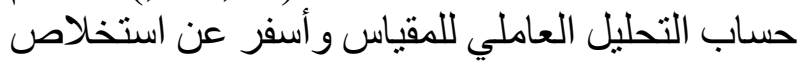
(11) عاملا استو عبت (58,19) من التباين الكلي. ثانيا :- مقياس الاستقرار الاسري إعداد فَّيصل يونس وصفاء مرسي (2012)

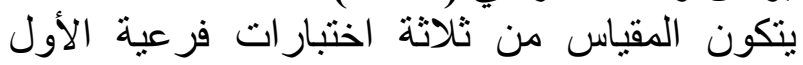

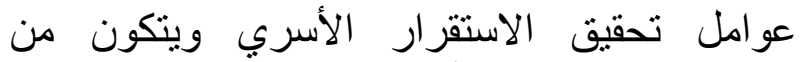

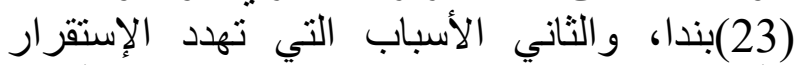
الأسري ويتكون من (40) بندا، والاني والثالث : أهمية الإنية الاستقرار الأسري ونئ ويتكون من (23) بندا وتنوه

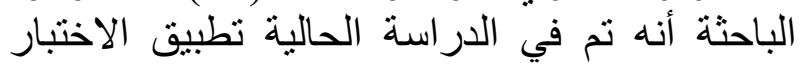

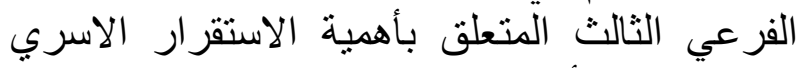

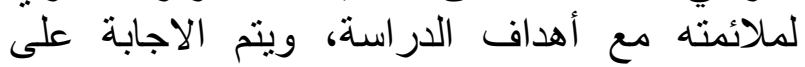


لمقياس الإتجاه نحو قبول الآخر بين (45, ،63 6) )؛

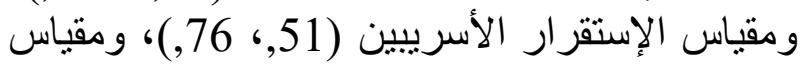

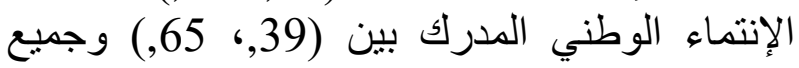

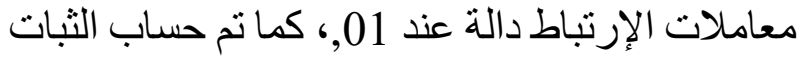

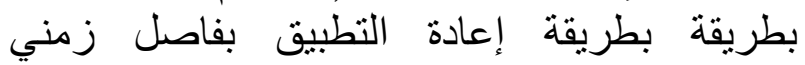

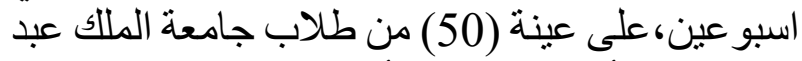
العزيز، و أيضا بطريقة ألفا كرونباخ ، وبطريقة طئة التجزئة النصفية وبعد التصحيح بمعامل سبيرمان براون، والجدول التالي يوضح الهفي معاملات الثبات لمقاييس الدر اسة اجنة

جدول (2) معاملات ثبات مقاييس الدراسة

\begin{tabular}{|c|c|c|c|}
\hline التجزئة النصفية & ألفا كرونباخ & إعادة التطبيق & معاملات الارتباط المقلييسل ـ ـ \\
\hline$* *, 68$ & $* *, 76$ & $* *, 73$ & الإتجاه نحو قبول الآخر \\
\hline$* *, 59$ & $* *, 77$ & $* *, 70$ & الإستقرار الأسري \\
\hline$* *, 82$ & $* *, 81$ & $* *, 64$ & الإنتماء الوطني المدرك \\
\hline
\end{tabular}

وينص على:- يوجد انتشار للاتجاه نحو قبول الآخر

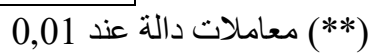
لاى عينة من الثباب السعودي. وللإجابة علي هذا التساؤل تم حساب المتوسطات التهاب

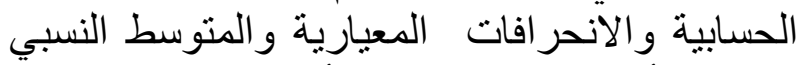

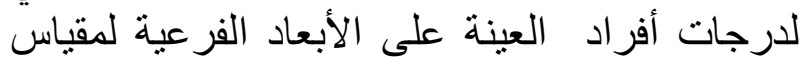

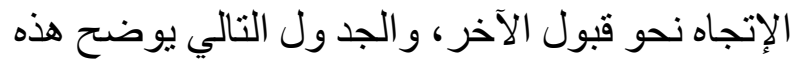
يتضح من الجدول السابق تمتع مقاييس الدر اسة بدرجة

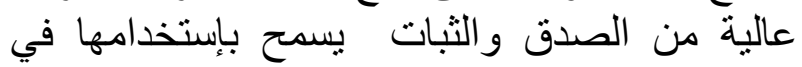
الدانة الاسة الحالية. نتائج الار اسةة:عرض نتيجة الفرض الأول ومناقشتها

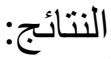
جدول رقم (3) المتوسطات الحسابية والانحر افات المعيارية والمتوسط النسبي لمقياس الإتجاه نحو قبول الآخر

\begin{tabular}{|c|c|c|c|c|}
\hline الترتيب & المتوسط & الانحراف & المتوسط & الإتجاه نحو قبول الآخر \\
\hline 3 & 2,01 & 4,69 & 17,55 & روئية الذات \\
\hline 4 & 1,42 & 2,65 & 12,42 & روئية الآخر \\
\hline 1 & 3,01 & 8,56 & 30,20 & رؤية تحررية \\
\hline 2 & 2,57 & 6,30 & 25,26 & الدرجة الكلية \\
\hline
\end{tabular}

يتضح من الجدول السابق وجود مستوى للاتجاه نحو وتتفق نتيجة الدراسة الحالية مع نتيجة ميشيل مجلع

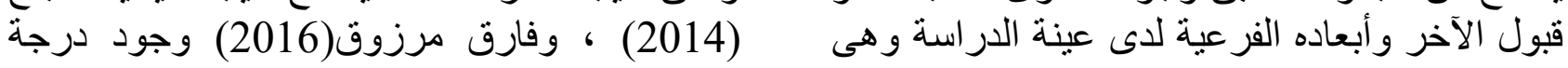

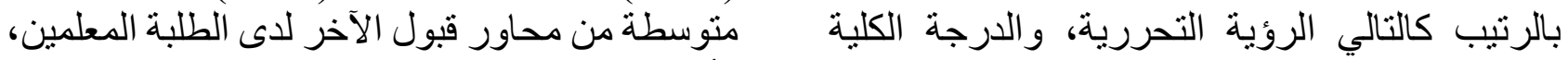

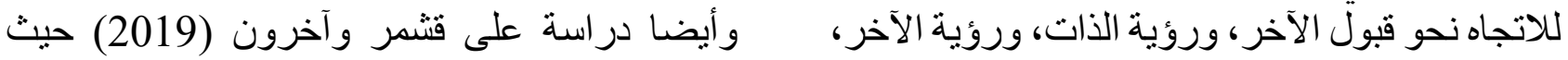


الآخرين، كما يسهم بشكل فعال في خلق جيل واع قادر على تحمل المسئولية وقيادة المرحلة القادمة بشكل فئل

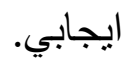

عرض نتيجة الفرض الثاني ومناقشتنها

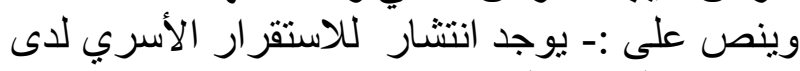

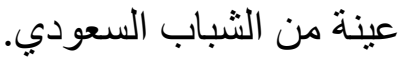

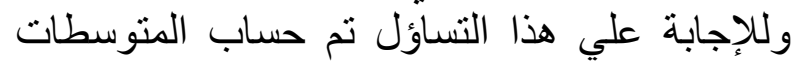

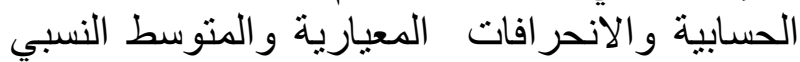

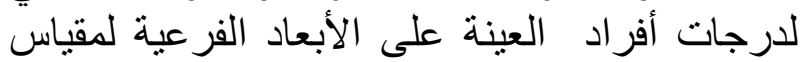

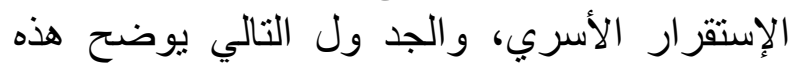

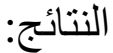

اهتمت بالتحقق من واقع ثقافة قبول الآخر في الجامعات الفلسطينية و اللبنانية و الأردنية لأى طن طلبتها

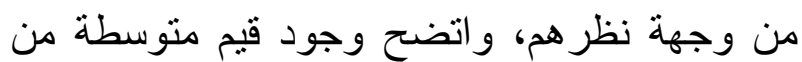

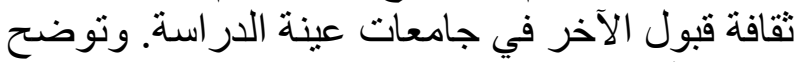

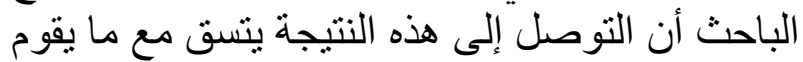

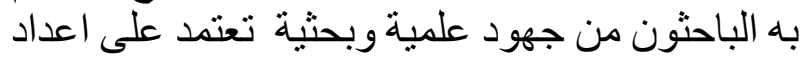

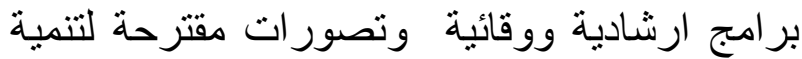

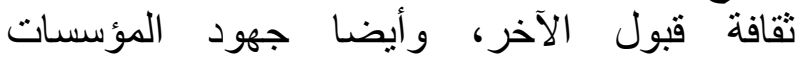

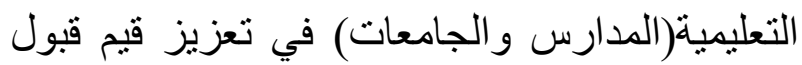

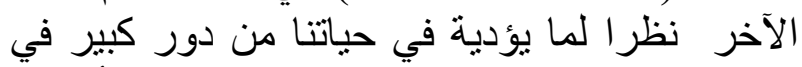

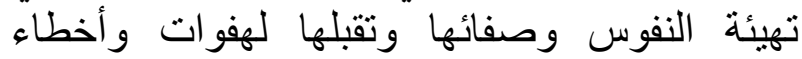
جدول رقم (4) المتوسطات الحسابية والانحرافات المعيارية والمتوسط النسبي لمقياس الإستقرار الأسري

\begin{tabular}{|c|c|c|c|}
\hline المتوسط & الاتحراف & المتوسط & الإستقرار الأسري \\
\hline النسبي & المعياري & الحسابي & \\
\hline 1,32 & 4,69 & 7,48 & أهمية الإسقرار الأسرى \\
\hline
\end{tabular}

من الجدول السابق يتضح أن وجود مستوى منوسط وتثثير الباحثة إلى أهمية وجود مستوى من الأستقرار الأسري داخل الأسرة لكي يتسنى لها القيام بوظائفها

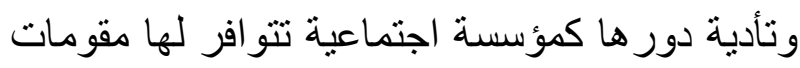

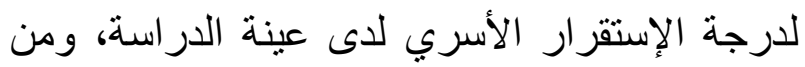

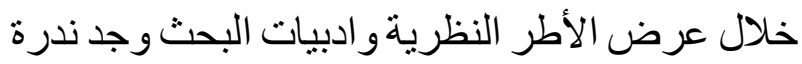
نجاح الأسرة وتر ابطها. عرض نتيجة الفرض الثالث ومناقشتها وينص على :- يوجد انتشار الانتماء الوطني المدرك لكرهن لاى عينة من الثباب السعودي.

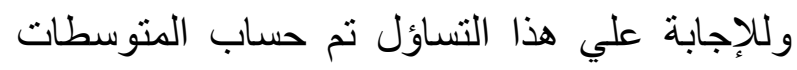

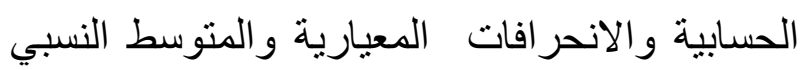
لارجات أفراد العينة على الأبعاد الفرعية لمقياس

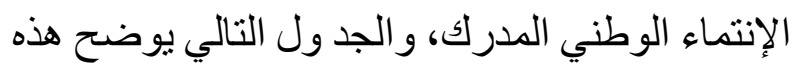
النتائج: - (النباء في الدراسات التي اهتمت بالتحقق من مستوى الاطرى

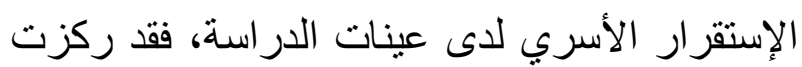

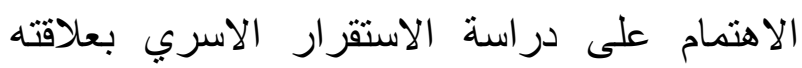

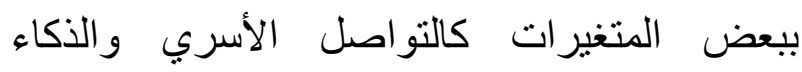
الوجداني. بالرغم من أهمية التحقق من مستوى الأنى الاستقرار الأسري وفي هذا الصدد أثنارت دراسة

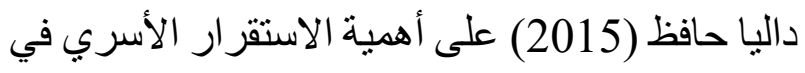

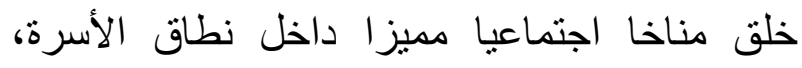

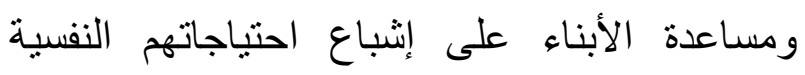
و الاجتماعية، ويسود جو المودة و الرحمة في الأسرة. 


\begin{tabular}{|c|c|c|c|c|}
\hline الترتيب & النسبي & المعياري & المتوسط الحسابي & الإنتماء الوطني المدرك \\
\hline 3 & 1,67 & 2,45 & 11,43 & تقاير الذات \\
\hline 2 & 2,12 & 4,21 & 20,78 & التوصل \\
\hline 1 & 3,44 & 7,59 & 28,98 & فعالية الأات \\
\hline 4 & 1,23 & 1,87 & 8,56 & الدرجة الكلية \\
\hline
\end{tabular}

يتضح من الجدول السابق وجود مستوى منوسط لوكرية ، ينبغي معها رفع مستوى وعي الثباب

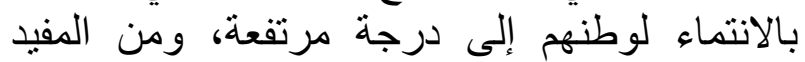

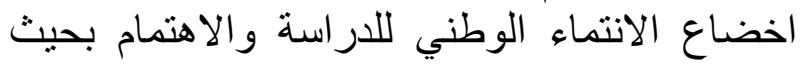

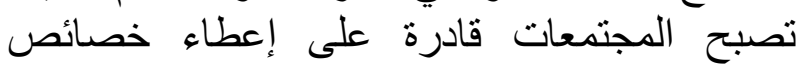

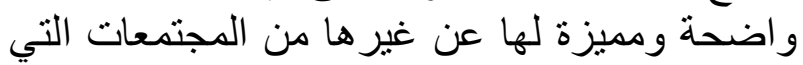

يضعف الانتماء فيها.

عرض نتيجة الفرض الرابع ومناقشتها

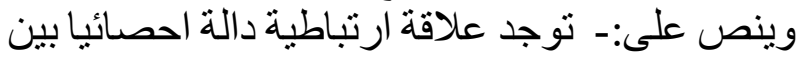

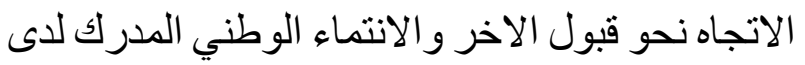
عينة من الثباب السعودي. للانتماء الوطني المدرك و أبعاده الفرعية لدود لدئي عينة

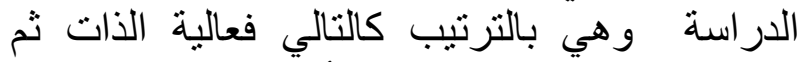

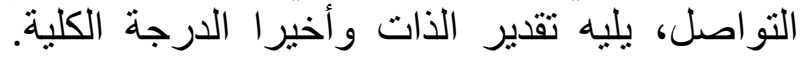

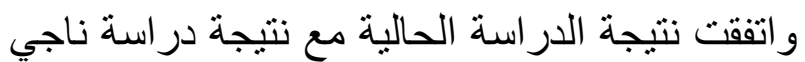
الحربي(2010) حيث ظهر أن مدى انتشار الانتماء الوطني وصل الى (78\%) لدى عينة الدر اسة، و أيضا التيا در اسة محمد اسماعيل و غادة وشحاته (2013)حيث

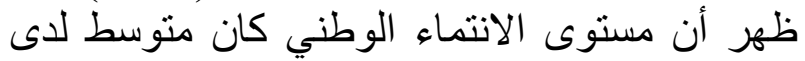

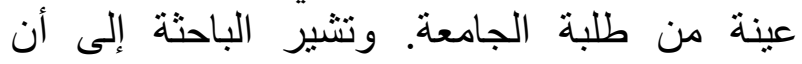

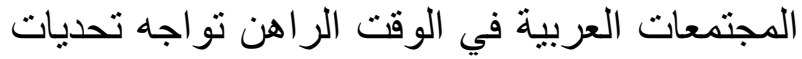

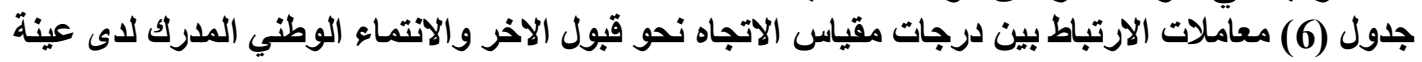

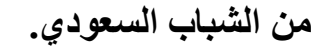

\begin{tabular}{|c|c|c|c|c|}
\hline الارجة الكلية & فعالية الأتات & التواصل & تقدير الذات & _ـلالانتماء الوطني المدرك \\
\hline$* *, 516$ & $* *, 321$ & $* *, 432$ & $* *, 638$ & روئية الذات \\
\hline$* *, 542$ & $* *, 482$ & $* *, 467$ & $* *, 349$ & روئية الآخر \\
\hline$* *, 321$ & $* *, 419$ & $* *, 515$ & $* *, 552$ & رؤية تحررية \\
\hline$* *, 662$ & $* *, 612$ & $* *, 591$ & $* *, 702$ & الارجة الكلية \\
\hline
\end{tabular}

تعزيز الإنتماء الوطني المدرك لدى الثباب بحيث

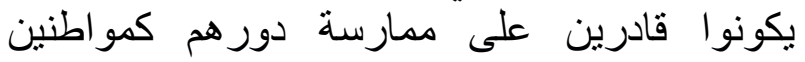

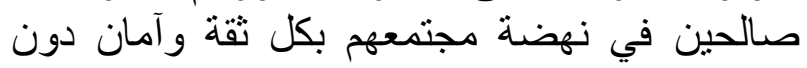
التعدي على حقوق الآخرين، و اكساب الثباب مفاهيم

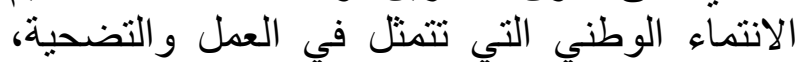
و الاعتز از بالوطن وقياء الانياته. عرض نتيجة الفرض الخامس ومناقشتها وينص على :- توجد علاقة ارتباطية دالة احصائيا

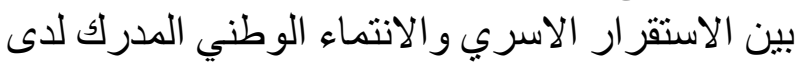
عينة من الثباب السعودي.

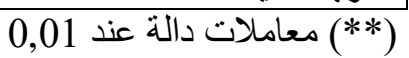

يتضج من الجدول السابق وجود ارنباط دال دال الاتجاه نحو قبول الآخر(الأبعاد الفرعية والإن وجة الإنة الكلية)

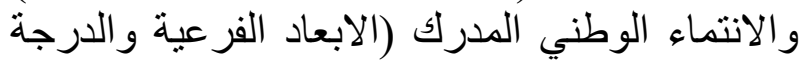
الكلية)، وتر احت معاملات الارتباط بين (12,32، 70,)؛

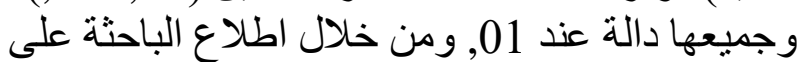

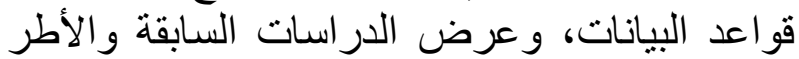

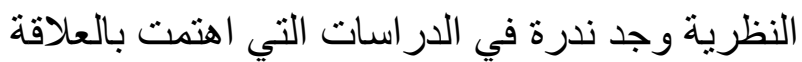

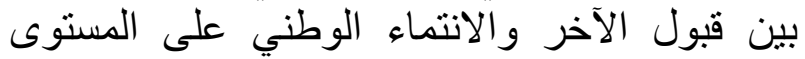

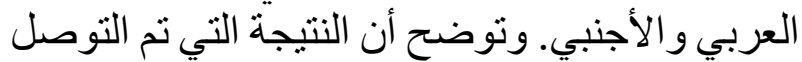

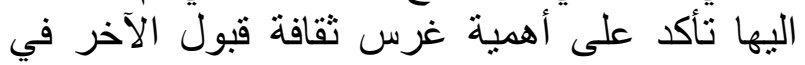

جدول (7) معاملات الارتباط بين درجات الاستقرار الاسري والانتماء الوطني المدرك لدى عينة من الثباب السعودي.

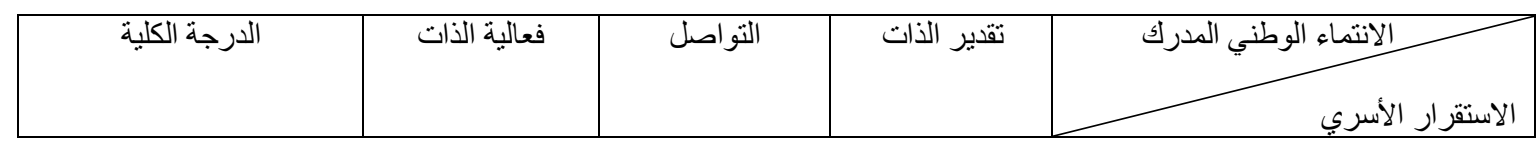




\begin{tabular}{|c|c|c|c|c|}
\hline$* *, 436$ & $* *, 381$ & $* *, 437$ & $* *, 335$ & أهمية الاستقر ار الأسري \\
\hline$* *, 652$ & $* *, 592$ & $* *, 567$ & $* *, 541$ & الدرجة الكلية \\
\hline
\end{tabular}

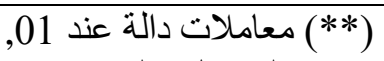

اللازمة لإشباع احتياجاتهم في مر احل النمو المختلفة،

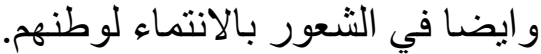

عرض نتيجة القرض السادس ومناقشتئها

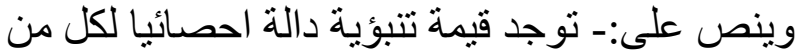

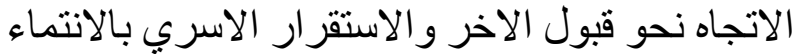

الوطني المدرك لدى عينة من الثباب السعودي.

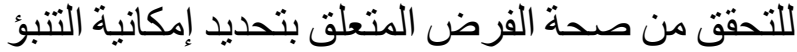

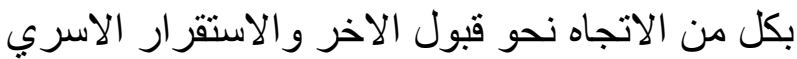

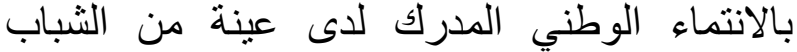
السعودي.و استخدمت الباحثة تحليل الانحدار المتعدد،

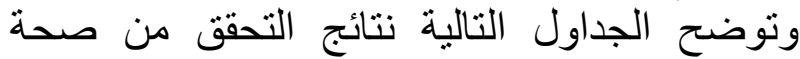

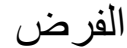

يتضج من الجدول السابق وجود ارتباط دال بناء بين الإستقرار الأسري والانتماء الوطنى المدرك الأك (الأبعاد

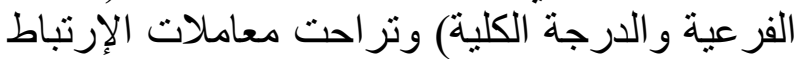

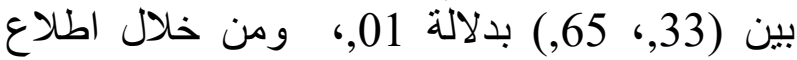

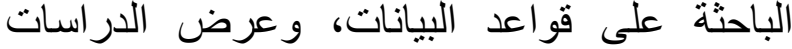

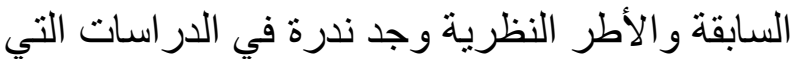

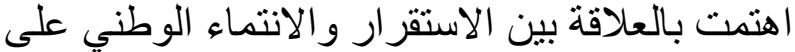

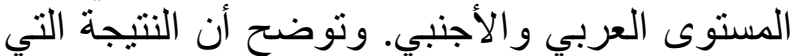
تم التوصل اليها تأكد على أهمية الاستقرار الأسي الأسري

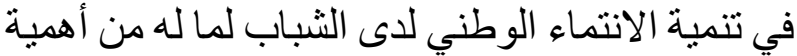

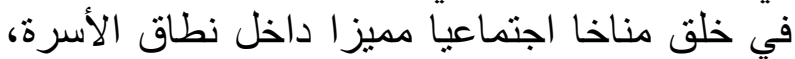

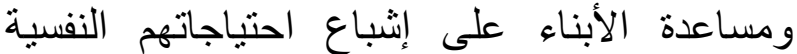
و الاجتماعية، ويسود جو المودة والراء الرحمة في الأسرة،

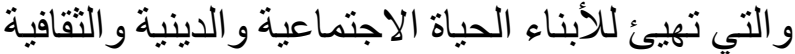

جدول رقم (8) تحليل التباين الانحدار الاتجاه نحو قبول الاخر والاستقرار الاسري

\begin{tabular}{|c|c|c|c|c|c|c|}
\hline الدلالة & قيمة ف & متوسط المربعات & الحرية & مجموع المربعات & مصدر التباين & المتغيرات \\
\hline \multirow{3}{*}{0.000} & \multirow{3}{*}{21.572} & 8516.297 & 2 & 20036.437 & الاتحدار & \multirow{3}{*}{ الالاختر الاستراه نحو قبول } \\
\hline & & 553.167 & 402 & 192454.521 & البواقي & \\
\hline & & & 404 & 211491.143 & المجموع & \\
\hline
\end{tabular}

إحصائيا عند مستوى 0.01، مما بدل على إمكانية

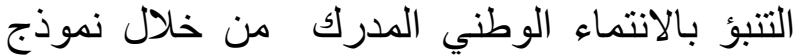

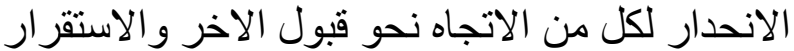
الاسري. يتضح من الجدول السابق وجود تأثثر دال إحصائيا

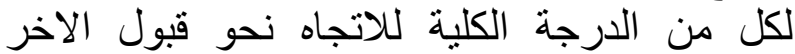
والاستقرار الاسري في التنبؤ بالانتماء الوطنة فئهي المدرك؛ حيث كانت فيمة ف الأن (21.572) وهي دالة

جدول رقم (9) نتائج الانحدار المتعدد الاتجاه نحو قبول الاخر والاستقرار الاسري في التنبوُ بالإنتماء الوطني المدرك لاي عينة الدراسة الاست

\begin{tabular}{|c|c|c|c|c|c|c|}
\hline مستلوي & اختبار (ت) & بيتا & مربع معاط & نسبة ج إسهام & المتغيرات المستقلة & المتغير التابع \\
\hline 0.000 & 14.017 & 165.090 & \multirow{3}{*}{0.094} & \multirow{3}{*}{34,71} & الثبات & \multirow{2}{*}{ الوطني } \\
\hline 0.026 & 3.234 & 0.154 & & & & \\
\hline 000 & 5.470 & 0.840 & & & & \\
\hline
\end{tabular}

كانت قيمة اختبار (ت) للاتجاه نحو قبول الآخر يتضح من الجدول السابق أن نسبة إسهام نموذج 0.05 (3.234) وهي دالة إحصائيا عند مستوى دلالة الانحدار للاتجاه نحو قبول الآخر والاستقر ار الأسري مما يدل على إمكانية التنبؤ بالإنتماء الوطني المدرك في التنبؤ بالانتماء الوطني بلغت 34,71 \% ، حيث 
- ضرورة اهتمام المؤسسات الاعلامية بتقديم بر امج

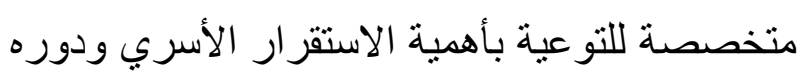
في دعم الانتماء الوطني. مقترحات الاراسة:ـ فعالية برنامج ارشادي لتتمية الاتجاه نحو قبول الآخر لاى عينة من طلاب الجامعة.

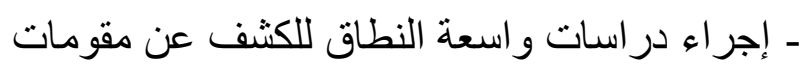
الاستقر ار الأسري لدى الثباب. ـ دراسة الإتجاه نحو قبول الآخر و وعلاقته بكل من الآن القابلية للإستهو اءهو أحادية الرؤية.

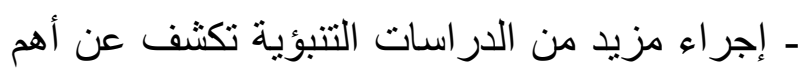
العو امل المنبئة بالإنتماء الوطني من التراه (1) تم تمويل هذا المشروع من قبل عمادة البحث

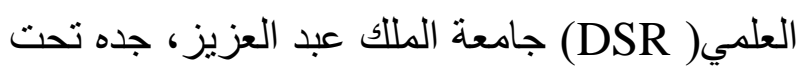
منحة رقم (Z:4-246-1441) وتئقدام الباحثة بالثكر لعمادة البحث العلمي على الدعم التقني و المادي للبحث.

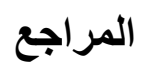

\section{المراجع العربية}

- الجوهرة حمادة السهلي و و وألفت عبد الله العربي(2018). دور القصص في تنمية قبول الآخر لاى عينة من أطفال الروضة بدرة لدافظة حفر الباطن. المجلة العربية للإعلام وثقافة الطفل، (2)، 109-45.

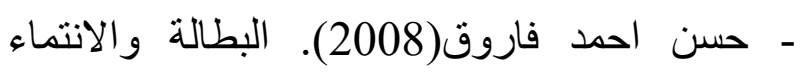
الوطني لدى خريجي جامعة المنيا: دراسة ميدانية .

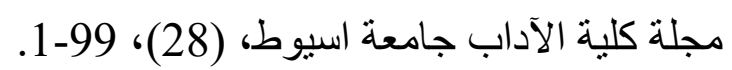
ـ خلود عبد الله ملياني(2017). دور الاعلام الجديد وشبكات التواصل الاجتماعي في تعزيز قيم الانتماء
من خلال الاتجاه نحو قبول الآخر ، كما أن قيمة اختبار (ت) للاستقرار الأسري كانت (5.470) وهي دالة فئلة فئل إحصائيا عند مستوى دلالة 0.01 ، مما يدل على الانى

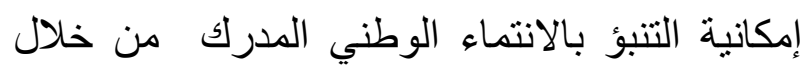
الاستقر ار الأسري كما يوضح الجدول أن قيمة معامل بيتا للثبات النموذج النئري كانت (165.090)، وقيمة معامل الثابت للاتجاه نحو قبول الآخر (0.154)، وقيمة معامل الثابت للاستقر ار الأسري (0.840) مما يدل على أن زيادة درجة واحدة

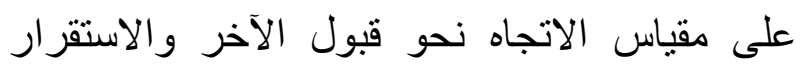
الأسري ، فإنه يمكن التنبؤ بالانتماء الوطني المدرك الأول وفقا لمعادلة الانحدار التالية:

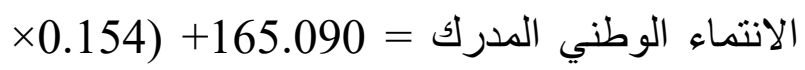
الاتجاه نحو قبول الآخر ) + (0.840×الاستقرار الأسري ) وتتفق نتيجة الفرض الحالي مع ما تم الأن

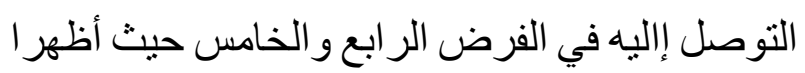

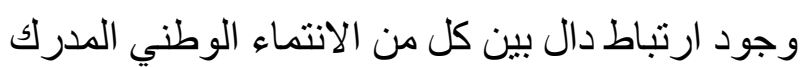

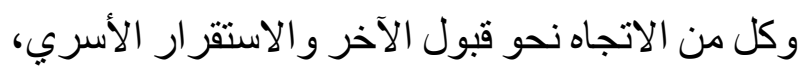
مما يوضح ظهور هما كمتغيرات منبئة بالانتماء

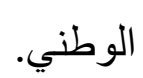
توصيات الار اسة ـ توجيه أنشطة الجامعة للبحث على تعزيز ثقافة تقبل الآخر. ـ تضمين المقررات الجامعية المزيد من المواد التي تعزز ثقافة تقبل الآخر وذللك لجميع الكليات.

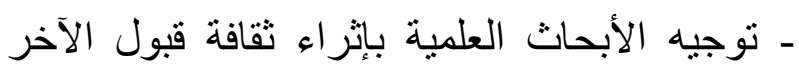
و الأخذ بنتائجها وتوصيه الابحاتهات 
النساء العاملات و غير العاملات. مجلة كلية الاداب، $.666-635 \cdot(130)$ - صفاء اسماعيل مرسي(2012). الذكاء الوجداني لدى الزوجات و علاقته بالاستقرار الاسري. مجلة در اسات عربية في علم النفس، 11(3)، 499-469.

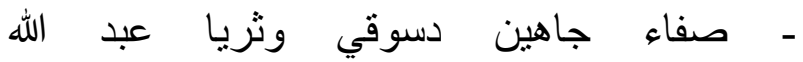
جنيدابي(2018). فعالية برمجية الكترونية مقترحة لمعلمات اللغة العربية قبل الخدمة في تنمية قدرتهن على استخدام المنهج الخفي في مولجهة التطرف والارهاب وتتمية الاتجاه نحو قبول الآخر المجلة التربوية جامعة الطائف،(53)، 456- 493. ـ عبير عبد المنعم فيصل(2015). برنامج مقتر ح قائم على أسلوب الحوار في مادة علم الإجتماع لطلاب المرحلة الثانوية لتنمية قيم قبول الآخر. مجلة الجمعية التربوية للدر اسات الاجتماعية، (70)، 152-117. - عثمان بن صالح العامر(2010). أثر الانفتاح الثقافي على مفهوم المواطنة لدى الثباب السعودي دراسة استكثافية. اللقاء الثالث عثر لقتدة العمل التربوي في المملكة العربية السعودية، (1)،30-1. ـ على لطفي قتنمر وحياة عبد الحافظ الأحمد وهاديا عبد الرحيم حمود وسميرة على عريس(2019). دور الجامعات الفلسطينة و اللبنانية والأردنية بتعزيز ثقافة قبول الآخر لدى طلبتها من وجهة نظرهم. مجلة دراسات في العلوم الانسانية والاجتماعية، .330-296،(16)2 - على نجيب عو اد(2015). التربية على المواطنة والانتماء وثقافة الحوار: تجربة دولية في تعزيز قيم
الوطني لدى طلاب الجامعات السعودية . أبحاث الملتقى العلمي الأول لكية اللآداب و العلوم الانسانية، جامعة الملك عبد العزيز(1)، 233-291. ـ داليا نبيل حافظ(2015). المناخ الأسري و علاقته بالمخاوف الاجتماعية لدى الأطفال. مجلة دراسات عربية في علم النفس، 14(1)، 217-163. - زينب محمد عبد الجليل ونورة مسفر الزهراني(2011).الاستقرار الاسري وعلاقته بأساليب اتخاذ القرارات لدى الأسر السعودية. مجلة بحوث كلية التربية النوعية، مصر، (21)، -409

- سامية سمير شحاته(2012). مستوى الانتماء المدرك و الخصائص السيكومترية لمقياس الانتماء لاى طلاب الجامعة. مجلة دراسات عربية في علم النفس، 11 (3)، 539-501-5 (5). - سمية حسام ابو بكر(2013). الانتماء الوطني و علاقته بمستوى الطموح لدى الاطفال. مجلة البحث العلمي في التربية، 14(2)، 620-607.

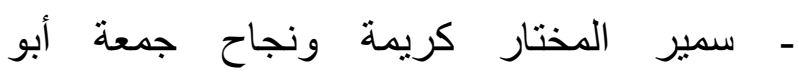
حرارة(2020). التواصل الأسري وانعكاسه على على الاستقرار الأسري: دراسة ميدانية على عينة من أعضاء هيئة التدريس المتزوجين بكلية التربية جامعة الزاوية ـ مجلة رماح للبحوث و الدر اسات ، (42)، $.480-457$ - شذي صادق البنى ومحمد عبد الكريم الحوراني(2019). عمل المرأة الإمارتية و أثره في الاستقرار الأسري دراسة مقارنة بين عينتين من 
العالمي الثاني عشر للندوة العالمية للشباب الإسلامي: الثباب في عالم متغير ،(2)، 1075-1023.

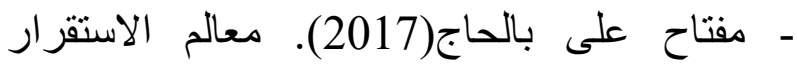

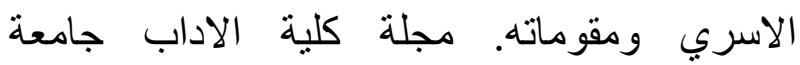
مصر اته،(9)، 156-121. - ميشيل صبحي مجلع(2014). بنية الاتجاه نحو قبول الاخر ودرجة شيو عه لدى عينة من المجتمع المصري

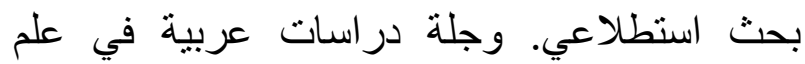
النفس، 13(2)، 216-169. ـ ناجي عرض الحربي(2010). دور منهج التربية

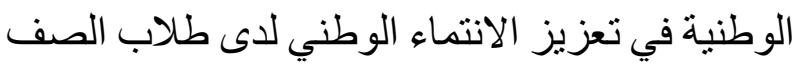
الثالث الثانوي بالمملكة العربية السعودية. رسالة التالة دكتور اه، كلية التربية، جامعة طيبة.

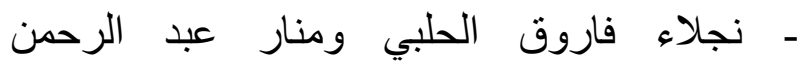
خضر(2010). إدارة الوقت لادى الثباب الجامعي

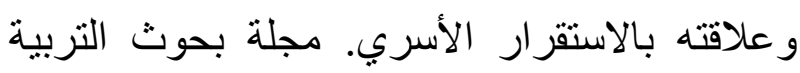
النوعية، (16)، 271-238. ـ نجوى احمد السرحاني(2014)، استر اتيجية تربوية مقترحة للجامعات السعودية في مواجهة التحديات السعودية في مواجهة التحديات الثقافية وتعزيز الانتماء الوطني لدى طلبتها. رسالة دكتور اه، كلية الدر اسات العليا، الجامعة الاردنية. - وليد سيد محمد و عاصم السيد اسماعيل و أماني على الهيل رجب(2018). وحدة مقترحة قائمة على حلى للى المشكلات المرتبطة بالتطرف الفكري لتنمية قيم الانتماء الوطني والتفكير الناقد لاى تلاميذ المرحلة

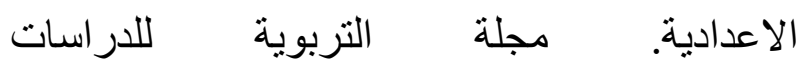
الاجتماعية،(99)، 197-235.

\section{ثانيا المراجع الأجنبية}

- Al majajdah, Bak (2010). The role of Islamic culture books in the dialogue of civilizations
المواطنة ومكافحة الارهاب. الندوة العلمية حول تعزيز قيم المو اطنة ودور ها في مكافحة الارهاب. ـ فاروق جعفر مرزوق(2016). استدماج ثقافة قبول الآخر في بر امج إعداد الطالب/ المعلم بجامعة القاهرة: تصور مقترح. مجلة العلوم التربوية، جامعة القاهرة، .68-29، (1)24

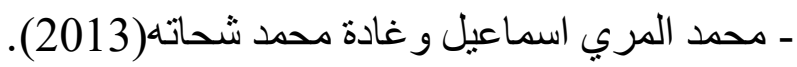
الانتماء الوطني لدى طلاب جامعة الزقازيق بعد ثورة 25يناير ـ مجلة در اسات تربوية ونفسية ، كلية التربية

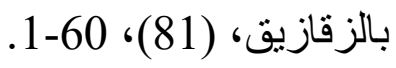
- محمد جلال السعايدة وحامد عبد الله طلافحة(2018). أثز تدريس مادة التربية الوطنية

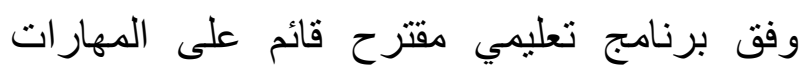
الاجتماعية في تتمية مفاهيم الانتماء الوطني لدى لئي طلاب الصف العاثر الأساسي في الأردن.مجلة

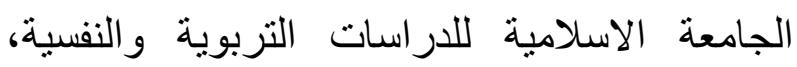
.448-430،(2)27 - مروى حسين اسماعيل(2017). برنامج إثرائي مقترح في الجغرافيا على بعض القضايا السياسية

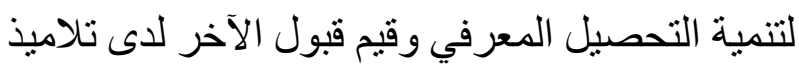
المرحلة الإعدادية. المؤتمر الدولي للجمعية التربوية

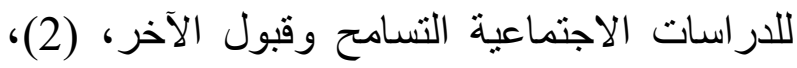
.766-726 ـ مشهور الجباري سرور(2015). العو امل المساهمة في تشكيل الانتماء الوطني لدى طلبة الجامعات الفلسطينية طلبة جامعة القس نموذجا. المؤتمر through the dissemination of a culture of dialogue and tolerance with the other. Jordan, 
An-Najah University Journal of Research (Humanities), 24, (8), 2271-2288- .

- Aldoughlia, R(2019).The symbolic construction of national identity and belonging in Syrian nationalist songs (from 1970 to 2007). Contemporary levant 4(2), 141-154.
- Hirsch, R. (2010) "World Citizenship Education: Form Concept to Realization". Online Submission. - Jyyad, Z., El-Din, M. (2012). Public relations program for the development of the values of tolerance and the culture of dialogue with the other Tikrit University, Faculty of Arts, Journal of Literature Farahidi, (11), 520-553.

\title{
Predictive ability to attitude toward acceptance of others and family stability to Strengthen the national belonging perceived among a sample of Saudi youth
}

\author{
Fatma Khalifa Elsayed \\ professor of Clinical Psychology- Faculty of Arts \\ king AbdulAziz University- Jeddah- Saudi Arabi
}

\begin{abstract}
Prevalence of attitude toward acceptance of others, family stability and national belonging perceived among a sample of Saudi youth, also identify the relationship between attitude toward acceptance of others and national belonging perceived, and the relationship between family stability and national belonging perceived, and the Predictive ability to attitude toward acceptance of others and family stability to Strengthen the national belonging perceived, This study includes a sample of Saudi youth(N=205) In this study the researcher used attitude toward acceptance of others Scale, family stability Scale, and national belonging perceived Scale, the result showed that a Prevalence of attitude toward acceptance of others, family stability and national belonging perceived among a sample of Saudi youth, there is a relationship between attitude toward acceptance of others and national belonging perceived, a relationship between family stability and national belonging perceived, and there is a Predictive ability to attitude toward acceptance of others and family stability to Strengthen the national belonging perceived.

Key words:- Attitude toward acceptance of others - Family stability - National belonging perceived - Saudi youth
\end{abstract}

